\title{
Techno-economic Assessment of Integrated Hydrothermal Liquefaction and Combined Heat and Power Production from Lignocellulose Residues
}

\author{
Mohamed Magdeldin ${ }^{* 1}$, Thomas Kohl ${ }^{2}$, Mika Järvinen ${ }^{3}$ \\ ${ }^{1}$ Department of Mechanical Engineering, Thermodynamics \& Combustion Technology Laboratory, \\ School of Engineering, Aalto University, Otakaari 4 (K1), 02150 Espoo, Aalto, Finland \\ e-mail: mohamed.magd@aalto.fi \\ ${ }^{2}$ Department of Mechanical Engineering, Thermodynamics \& Combustion Technology Laboratory, \\ School of Engineering, Aalto University, Otakaari 4 (K1), 02150 Espoo, Aalto, Finland \\ e-mail: thomas.kohl@aalto.fi \\ ${ }^{3}$ Department of Mechanical Engineering, Thermodynamics \& Combustion Technology Laboratory, \\ School of Engineering, Aalto University, Otakaari 4 (K1), 02150 Espoo, Aalto, Finland \\ e-mail: mika.jarvinen@aalto.fi
}

Cite as: Magdeldin, M., Kohl, T., Järvinen, M., Techno-economic Assessment of Integrated Hydrothermal Liquefaction and Combined Heat and Power Production from Lignocellulose Residues, J. sustain. dev. energy water environ. syst., 6(1), pp 89-113, 2018, DOI: https://doi.org/10.13044/j.sdewes.d5.0177

\begin{abstract}
Waste biomass as a mean for global carbon dioxide emissions mitigation remains under-utilized. This is mainly due to the low calorific value of virgin feedstock, characterized generally with high moisture content. Aqueous processing, namely hydrothermal liquefaction in subcritical water conditions, has been demonstrated experimentally to thermally densify solid lignocellulose into liquid fuels without the pre-requisite and energy consuming drying step. This study presents a techno-economic evaluation of an integrated hydrothermal liquefaction system with downstream combined heat and power production from forest residues. The utilization of the liquefaction by-products and waste heat from the elevated processing conditions, coupled with the chemical upgrading of the feedstock enables the poly-generation of biocrude, electricity and district heat. The plant thermal efficiency increases by 3.5 to $4.6 \%$ compared to the conventional direct combustion case. The economic assessment showed that the minimum selling price of biocrude, based on present co-products market prices, hinders commercialization and ranges between 138 EUR to 178 EUR per MWh. A sensitivity analysis and detailed discussion on the techno-economic assessment results are presented for the different process integration and market case scenarios.
\end{abstract}

\section{KEYWORDS}

Hydrothermal liquefaction, Biocrude, Combined heat and power, Techno-economic assessment.

\section{INTRODUCTION}

Hydrothermal Liquefaction (HTL) is a promising technology that has continued to show favorable processing of solid biomass into liquid products (known hereafter as Biocrude) to act as either substitutes or drop-ins for fossil fuels or chemicals [1].

\footnotetext{
${ }^{*}$ Corresponding author
} 
In principal, HTL is a thermochemical conversion step in which aqueous processing of biomass with substrate moisture or additive water takes place at elevated pressures, between 100-400 bar, and temperatures, between 210 to $370{ }^{\circ} \mathrm{C}$ [2]. Where, lower and higher temperature profiles favor the char and syngas yields respectively [3]. The higher pressure maintains liquid processing and eliminates dissipative heat lost in the form of evaporated water by the necessary drying step for the more traditional thermochemical conversions, namely pyrolysis [4]. Direct liquefaction or HTL of solid carbon was historically developed for coal due to the oil crisis in the early 1970s [5]. More recently, literature based on experimental batch investigations has redirected the focus to the conversion of a wide variety of green carbonaceous slurries [6]. Pilot scale setups have been reported for continuous operation with model compounds that depict constituents of biomass slurries [7]. Commercial solutions such as Shell's HTU ${ }^{\circledR}$ process and Hydrofraction $^{\mathrm{TM}}$ by Steeper Energy ApS in the Denmark have also been reported based on a wood to renewable oil concept [8].

Water's thermo-physical properties at the acute conditions of HTL processing (subcritical conditions), vary significantly and are the main drivers for diverse sets of degradation mechanisms for lignocellulose structures into solid, liquid and vapor products [9]. The HTL primary product is mostly de-oxygenated hydrocarbons found in a hydrophobic crude phase with secondary by-products of water soluble organics, solid char and a Carbon dioxide $\left(\mathrm{CO}_{2}\right)$ rich gas [10]. The governing conversion sequences of the organic content could be summarized as [5]: Hydrolysis by reactive water diffusion into solid pores to yield smaller substructures, de-polymerization to smaller and soluble monomers, thermal degradation leading to new molecular rearrangements through dehydration, decarboxylation, $\mathrm{C}-\mathrm{O}$ and $\mathrm{C}-\mathrm{C}$ bond ruptures, and finally hydrogenlysis and hydrogenation of functional groups. The last step plays an important role from a quality perspective, defined mostly in literature as the removal rate of heteroatoms $(\mathrm{O}, \mathrm{N}$ and $\mathrm{S})$ and/or ash found in the final Biocrude yield [11]. Active hydronium $\left[\mathrm{H}_{3} \mathrm{O}\right]^{+}$and hydroxyl $[\mathrm{OH}]^{-}$ions, as a result of the higher ionic water product $\mathrm{pK}_{\mathrm{w}}$ in subcritical conditions, take part as a reactant or catalyst for the cleavage of carbon-hetero bonds [4]. The extracted nitrogen and sulphur compounds from the solid feed are distributed along the multi-phase products, and are reduced heavily within the Biocrude [12]. In the case of oxygen, it is removed in the form of either water $\left(\mathrm{H}_{2} \mathrm{O}\right)$ through dehydration or $\mathrm{CO}_{2}$ through decarboxylation, the two are competing pathways but both with positive effects [9]. The first leads to higher crude yield, while the later increases the $\mathrm{H} / \mathrm{C}$ ratio and as a result raises the crude heating value. The reported lower oxygen content between $12-30 \mathrm{wt} . \%$ is significantly lower than the original 40-50 wt.\% found in biomass. However, it is worth to mention that further upgrading to reduce the oxygen content (also residual sulphur and nitrogen), and meet the less than $0.1 \mathrm{wt} . \%$ levels found in fossil crude, is needed to match the corresponding thermo-physical performance and characteristics [13].

The competing degradation mechanisms are parametrically sensitive to the original biomass nature and the reactive conditions, as water properties change in the order of several magnitudes within the subcritical state [11]. Biocrude yields are generally in the range of 30-60 wt.\%, and as such thermal and material recovery from the HTL by-products has remained one of the process design challenges open to improvement. Akhtar et al. [14] in their review attempted to identify optimality conditions and process drivers for both Biocrude yield and quality. Final liquefaction temperature, residence times, rate of biomass heating and the size of biomass particles proved to have the largest influence. In addition, higher quenching rates at the outlet were identified as a limiting factor to the tendency of phenolic substrates for re-polymerization into solid residue [15]. Also, catalytic activity, both homogenous and heterogeneous, has been investigated extensively with mixed reports [4]. In general what could be concluded that catalyst 
addition, especially alkali salts, could drive the process away from re-polymerization mechanisms and limit char formation [16]. However, it has been reported to increase gas and water-soluble organic fractions and present process upscaling challenges related to catalyst stability, poisoning and regeneration or recovery. The benefits from catalytic processing could be accounted for by reactor or process design improvements to valorize the by-products, such as for in-situ heat generation or hydrogen production or for Combined Heat and Power (CHP) purposes [15]. Recently, studies have examined the isolation of other factors such as feedstock morphology to better understand the added-value of catalytic treatment [17]. It is worth to mention that experimental findings have reported that for non-catalytic processing, $330{ }^{\circ} \mathrm{C}$ and 210 bar present more favorable conditions for Biocrude yield [12].

Historically, several attempts have been presented in literature to deconstruct the step-wise conversion mechanisms under subcritical conditions for lignocellulose components to better understand and control the process [3]. Arturi et al. [18] concluded in their comprehensive multivariate data analysis review of 34 peer reviewed experimental articles on HTL that no common trend or regression models could be established for the wide range of feedstock and process conditions reported in literature. The two main barriers to mapping the conversion steps are the complex nature of the feed constituent's degradation mechanisms and the controllability and conditional limitation of experimental setups. To the authors' knowledge, currently there is an absence of a standardized, detailed and accepted kinetics or phase equilibria data for the interactions among the different biomass substructures and intermediaries within the hydrolyzed aqueous mixtures. As such, thermodynamic modelling for a constrained set of processing conditions remains the only reliable alternative approach for viability studies [2].

This article attempts to develop a thermochemical conversion model based on reported mass balance constraints for non-catalytic HTL treatment of Northern-hemisphere forest residues. At first, a predictive Linear Programming (LP) model identifies the specific process yield and closes the elemental conversion balance. The model findings are then utilized within a novel reactor concept developed in our group and simulated on Aspen Plus ${ }^{\circledR}$ commercial software for phase equilibria, fluids separation and thermal assessment. The HTL reactor system is integrated and simulated as part of complete plant layout to investigate Biocrude production coupled with downstream CHP production. The plant viability is determined through a Techno-Economic Assessment (TEA) based on the methodology described in [19]. Several reports of TEAs have been presented in literature for a wide range of potential industrial and waste slurries: woody biomass [20-22], algae [23, 24], food waste [25] and agricultural waste [26], with a primary focus thus far towards upgraded liquid fuel production for the transportation sector.

The limitation of Biocrude utilization in vehicle's internal combustion engines is the motivation behind investigating the hydrogenation upgrading route in literature [27]. The HTL gas and/or aqueous yield serve catalytic upgrading purposes by treatment for in-situ hydrogen production. CHP applications partially driven by the gas yield (partially by fossil sources) were investigated as a mean of matching the plants' thermal and power utility only in [21]. On the other hand, the utilization of the by-product HTL solid yield has been ignored either by the optimistic assumption of elimination (through catalytic treatment) or considered as a non-value waste stream. However, a recent study for a hydrothermal carbonization plant (where solid fuel is the primary product) showed both thermal and economic benefits from co-location and integration with a wood-fired CHP plant [28]. Similar observation was re-iterated for the utilization of the char by-product from the pyrolysis process as well [29]. In our HTL-CHP integration concept, the HTL process acts as a direct production unit for Biocrude from the forest residue feedstock as well as a mean of densifying the organic by-products for direct utilization in a CHP unit, 
connected to the national power grid and local District Heating Networks (DHN). The objective of the study is to quantify the thermal and economic added-value for different integration scenarios of the HTL Biocrude and by-products with a downstream CHP plant.

\section{STUDY METHODS AND MATERIALS}

This article primarily reports three main working tracks:

- Development and validation of a predictive mass balance model for the non-catalytic HTL system of a forest residue feedstock;

- The process design and simulation of a complete Gate-to-Gate plant layout for the HTL-CHP integration concept;

- Identify both the thermal and economic constraints of the integration options and establish through a sensitivity analysis conclusive insight for HTL process improvement and/or market penetration potential.

\section{Forest residue feedstock}

The data for the lignocellulose feedstock under consideration is based on the report by Hannula and Kurkela [30] for liquid fuel production in Finland through thermochemical conversion processes. The forest residue feedstock is a secondary/waste product from the harvesting of industrial wood, which consists of a higher proportion of bark and an as received moisture content of around 50\%. Traditional pre-treatment steps necessary for lignocellulose solids handling normally include chipping, crushing and drying, with the later step not required for the proposed liquefaction process [1]. The selection of the specific feedstock does not hinder the repeatability of the findings for others, however, it remains limited for raw feedstock (no pre-treatment or structural alteration), with a similar cellulose to hemicellulose to lignin ratios. The elemental analysis for the solid feedstock, as shown in Table 1, is used as input for our modelling purposes. The reported heating values are 8.6 and $20.67 \mathrm{MJ} / \mathrm{kg}$ for lower and higher respectively (used for thermal assessment), which is relatively similar to the calculated values (with the Boie correlation applied in Aspen Plus ${ }^{\circledR}$ ) of 8.1 and $20.18 \mathrm{MJ} / \mathrm{kg}$.

Table 1. Feedstock elemental analysis on mass basis extracted from [30]

\begin{tabular}{cccc}
\hline Proximate analysis - dry basis & {$[$ wt.\%] } & Ultimate analysis - wet basis & [wt.\%] \\
\hline Ash content & 1.33 & Carbon & 25.65 \\
Moisture (wet basis) & 50 & Hydrogen & 8.64 \\
Volatiles & 79.3 & Oxygen & 64.83 \\
Fixed carbon & 19.37 & Sulphur & 0.01 \\
& & Nitrogen & 0.2 \\
\hline
\end{tabular}

\section{Predictive hydrothermal liquefaction yield model}

The objective of the LP model developed on the General Algebraic Modelling System (GAMS) software is to predict the HTL reactor yield. The model is a resource allocation type, where the elemental feed is distributed among the products, minimizing the mass balance error, while matching the reported range in literature for both compounds and phase yields. The quantitative analysis is important for understanding potential effects and possibilities for further downstream processing of the HTL yield. Attempts in literature have been reported to establish specific kinetic decomposition rates or reproduce generalized transformation pathways in HTL conditions or identify regression models for key thermo-physical characteristics [18]. The highly sensitive nature of the HTL conversion to the feedstock nature and specific experimental setups (reactor and product separation system design) and to the operating conditions leads to a wide and 
varied range of compounds reported, in the magnitudes of hundreds at least if not thousands [1]. To minimize data distortions reported in the earlier referred work, the experimental runs used for data collection in our model are of a specified feedstock, wood (or forest) residues and for a limited range of operating conditions. The list of products, shown in Table 2 and the constrained conversions are based on three non-catalytic experimental results reported in [31-33]. All cases were reported in reactive conditions between temperature $280-330{ }^{\circ} \mathrm{C}$, pressures of $200-210$ bar and solid content between 2.5 and $10 \mathrm{wt} . \%$. The list of compounds found in the HTL yield are as following:

- First for the Biocrude and aqueous products, defined throughout the article as organic yield, the top 30 compounds are selected based on the reported mass fractions available from literature. The highest reported compound yield across the four case studies was set as the upper boundary constraint and vice versa for the lower boundary;

- Second, the gas products were based on reported mass composition in [34], ammonia and hydrogen sulphide were added to the list to account for nitrogen and sulphur partitioning into inorganic form. A $\pm 10 \%$ degree of freedom for the model accounted for an upper and lower boundary of the reported values;

- Third, balance compounds of reactive water (released from feedstock), char with elemental analysis based on [31] and ash were introduced.

Table 2. List of compounds to model the HTL reactor yield

\begin{tabular}{|c|c|c|c|}
\hline Organic yield & CAS No. & Organic yield & CAS No. \\
\hline Syringol $\left(\mathrm{C}_{8} \mathrm{H}_{10} \mathrm{O}_{3}\right)$ & $91-10-1$ & Syringaldehyde $\left(\mathrm{C}_{9} \mathrm{H}_{10} \mathrm{O}_{4}\right)$ & $134-96-3$ \\
\hline Benzaldehyde $\left(\mathrm{C}_{7} \mathrm{H}_{6} \mathrm{O}\right)$ & $100-52-7$ & Isoeugenol $\left(\mathrm{C}_{10} \mathrm{H}_{12} \mathrm{O}_{2}\right)$ & $97-54-1$ \\
\hline Guaiacol $\left(\mathrm{C}_{7} \mathrm{H}_{8} \mathrm{O}_{2}\right)$ & $90-05-1$ & 3-Methoxycatechol $\left(\mathrm{C}_{7} \mathrm{H}_{8} \mathrm{O}_{3}\right)$ & $934-00-9$ \\
\hline Diacetone alcohol $\left(\mathrm{C}_{6} \mathrm{H}_{12} \mathrm{O}_{2}\right)$ & $123-42-2$ & Propanoic acid $\left(\mathrm{C}_{3} \mathrm{H}_{6} \mathrm{O}_{2}\right)$ & 79-09-4 \\
\hline $\mathrm{o}, \mathrm{m}, \mathrm{p}-\mathrm{Creosol}\left(\mathrm{C}_{8} \mathrm{H}_{10} \mathrm{O}_{2}\right)$ & $93-51-6$ & 1,2-Benzenediol $\left(\mathrm{C}_{6} \mathrm{H}_{6} \mathrm{O}_{2}\right)$ & $120-80-9$ \\
\hline Vanillin $\left(\mathrm{C}_{8} \mathrm{H}_{8} \mathrm{O}_{3}\right)$ & $121-33-5$ & 2-Butanone $\left(\mathrm{C}_{4} \mathrm{H}_{8} \mathrm{O}\right)$ & $78-93-3$ \\
\hline Phenol $\left(\mathrm{C}_{6} \mathrm{H}_{6} \mathrm{O}\right)$ & $108-95-2$ & 3-methyl-Phenol $\left(\mathrm{C}_{7} \mathrm{H}_{8} \mathrm{O}\right)$ & $108-39-4$ \\
\hline $\begin{array}{l}\text { 1,4-Dimethoxy-2-methylbenzene } \\
\qquad\left(\mathrm{C}_{9} \mathrm{H}_{12} \mathrm{O}_{2}\right)\end{array}$ & $494-99-5$ & Isovanillic acid $\left(\mathrm{C}_{8} \mathrm{H}_{8} \mathrm{O}_{4}\right)$ & $121-34-6$ \\
\hline $\begin{array}{l}\text { Butylated hydroxytoluene } \\
\qquad\left(\mathrm{C}_{15} \mathrm{H}_{24} \mathrm{O}\right)\end{array}$ & $128-37-0$ & Toluene $\left(\mathrm{C}_{7} \mathrm{H}_{8}\right)$ & $108-88-3$ \\
\hline Diphenylamine $\left(\mathrm{C}_{12} \mathrm{H}_{11} \mathrm{~N}\right)$ & $122-39-4$ & $\begin{array}{l}\text { 4-Methyl-3-penten-2-one } \\
\qquad\left(\mathrm{C}_{6} \mathrm{H}_{10} \mathrm{O}\right)\end{array}$ & $141-79-7$ \\
\hline Furfural $\left(\mathrm{C}_{5} \mathrm{H}_{4} \mathrm{O}_{2}\right)$ & $98-01-1$ & 2-butanol $\left(\mathrm{C}_{4} \mathrm{H}_{10} \mathrm{O}\right)$ & $78-92-2$ \\
\hline Butyl isobutyl phthalate $\left(\mathrm{C}_{16} \mathrm{H}_{22} \mathrm{O}_{4}\right)$ & $84-69-5$ & $\begin{array}{l}\text { Cyclopropanecarboxylic acid } \\
\qquad\left(\mathrm{C}_{4} \mathrm{H}_{6} \mathrm{O}_{2}\right)\end{array}$ & $1759-53-1$ \\
\hline $\begin{array}{l}\text { 5-(Hydroxymethyl)furfural } \\
\left(\mathrm{C}_{6} \mathrm{H}_{6} \mathrm{O}_{3}\right)\end{array}$ & $67-47-0$ & Diethyl Phthalate $\left(\mathrm{C}_{12} \mathrm{H}_{14} \mathrm{O}_{4}\right)$ & $84-66-2$ \\
\hline 4-Isopropylthiophenol $\left(\mathrm{C}_{9} \mathrm{H}_{12} \mathrm{~S}\right)$ & $874-79-3$ & $\begin{array}{l}\text { 3-Hydroxybenzaldehyde } \\
\qquad\left(\mathrm{C}_{7} \mathrm{H}_{6} \mathrm{O}_{2}\right)\end{array}$ & $100-83-4$ \\
\hline Acetic acid $\left(\mathrm{C}_{2} \mathrm{H}_{4} \mathrm{O}_{2}\right)$ & 64-19-7 & Elaidic acid $\left(\mathrm{C}_{18} \mathrm{H}_{34} \mathrm{O}_{2}\right)$ & $112-79-8$ \\
\hline \multicolumn{4}{|l|}{ Gas yield } \\
\hline Methane $\left(\mathrm{CH}_{4}\right)$ & & Carbon dioxide $\left(\mathrm{CO}_{2}\right)$ & \\
\hline Hydrogen $\left(\mathrm{H}_{2}\right)$ & & Carbon monoxide (CO) & \\
\hline Ethane $\left(\mathrm{C}_{2} \mathrm{H}_{6}\right)$ & & Ethylene $\left(\mathrm{C}_{2} \mathrm{H}_{4}\right)$ & \\
\hline Propane $\left(\mathrm{C}_{3} \mathrm{H}_{8}\right)$ & & n-Butane $\left(\mathrm{C}_{4} \mathrm{H}_{10}\right)$ & \\
\hline Ammonia $\left(\mathrm{NH}_{3}\right)$ & & Hydrogen sulphide $\left(\mathrm{H}_{2} \mathrm{~S}\right)$ & \\
\hline \multicolumn{4}{|l|}{ Balance yield } \\
\hline $\begin{array}{c}\text { Water }\left(\mathrm{H}_{2} \mathrm{O}\right) \\
\text { Char }\left(\mathrm{C}_{0.42} \mathrm{H}_{0.41} \mathrm{O}_{0.17}\right)\end{array}$ & & Ash & \\
\hline
\end{tabular}


Finally, to account for the phase product conversion rates, the lowest reported specific yield for each of the by-product phase (gas and solids at 9.9 and $29.5 \mathrm{wt} . \%$ dry basis respectively) were set as additional constraints. The total number of 47 variables of the model represented the product yield in molar basis for each compound shown in Table 2, the specific phase yields, and the maximized objective variable, feedstock conversion to products (organics + solid + gases). The modelling approach was developed earlier in our research group at Aalto University [35] and has been applied successfully and reported in literature for various biomass thermochemical processes such as pyrolysis and torrefaction [29].

\section{The hydrothermal liquefaction Aspen Plus ${ }^{\circledR}$ model}

The modelled HTL yield from the LP model is used for the simulation of the plant layout in the commercial software Aspen Plus ${ }^{\circledR}$, a flowsheet of the HTL system is shown in Figure 1. The principal challenge in the development of a reliable model is the computation of the specific thermodynamic interactions of organic-aqueous mixtures, along with the prediction of phase equilibria for the highly asymmetric and multi-dimensional processing components of solids and fluids, polar and non-polar, within sub- critical mixtures [2]. An extensive list of propriety packages in Aspen Plus ${ }^{\circledR}$ was available for all the selected compounds, and the built-in estimation tool calculated any missing interaction parameters for the selected equation of state, Predictive Soave Redlich Kwong (PSRK). The plant solid feedstock as well as solid char and ash were defined as non-conventional compounds and thermodynamically simulated based on the built-in enthalpy and density coal correlations, HCOALGEN and DCOALIGT, respectively.

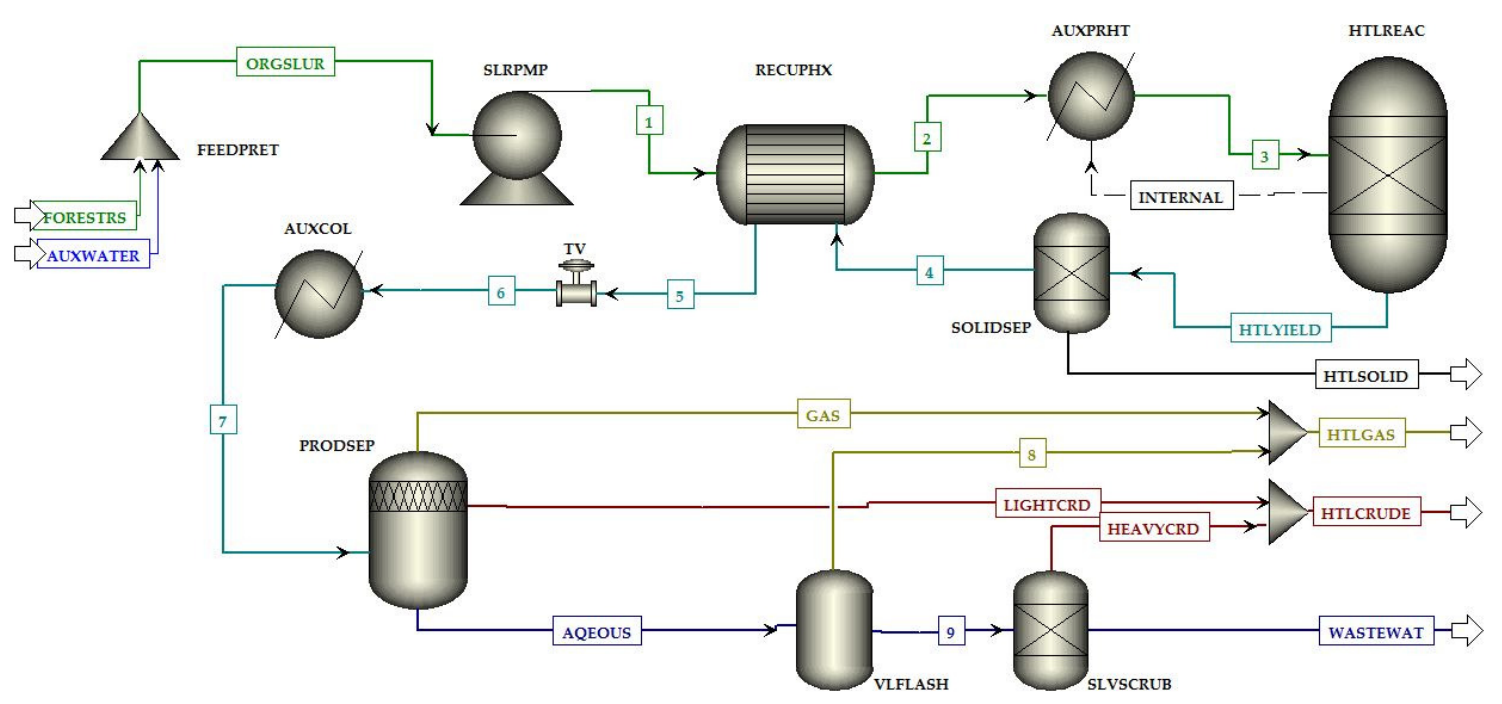

Figure 1. The HTL reactor system modelled on Aspen Plus ${ }^{\circledR}$

The reactor system starts from the upper left corner of Figure 1, where both the wet solid feedstock FORESTRS and feed water AUXWATER are mixed to match the set design condition of $15 \mathrm{wt} . \%$ solid content. The AUXWATER stream is simulated as pure water, however, it is envisaged in the plant assessment as a mixture of recycled aqueous stream from the wastewater treatment plant (not modelled) and 10\% make-up water. The plant input solid content is a conservative design condition, estimated for feasible pumping capabilities of lignocellulose slurries (maximum $18 \mathrm{wt} \%$ solids) reported from commercial vendors and compiled in [36]. The mixture enters a pre-treatment step modelled in Aspen Plus ${ }^{\circledR}$ as simply a mixer, while the overall plant evaluation accounted for the specified utility demands based on [37]. The selected coarse chipping unit reduces 
particle sizes of solids to a range of 5-10 $\mathrm{mm}$. The pre-treated slurry is then fed into the pumping stage were the slurry is upgraded over five sequential stage pumps of maximum 50 bar each. The pump system design is based on the rotary lobe pump system developed by Zeilfelder Pumpen GmbH [36]. Advantageous features of the pump are the upper temperature limits of $350{ }^{\circ} \mathrm{C}$, which would allow booster operation at reactor inlet conditions. The pump could also handle fibrous materials up to $10 \mathrm{~cm}$ due to the presence of a specialized chopper at the pump inlet and finally, if connected to a generator, the pump flow could reverse for liquid expansion and power production purposes.

The pressurized slurry is then preheated over two stages, first to $237^{\circ} \mathrm{C}$ through a heat recuperator with the HTL effluent. The recuperator is a shell and tube heat exchanger. Although commercial applications in the power and chemical industry mostly employ a supercritical fluid in the tubes with an ambient fluid in the shell, special design considerations for the shell as a pressure vessel is technically feasible [38]. The simulation model controlled the recuperator outlet temperature to maintain the following HTL reactor operation at adiabatic conditions with an optimal reactor outlet temperature for Biocrude yield at $330{ }^{\circ} \mathrm{C}\left(\Delta Q_{\text {reactor }}=0\right.$, shown in Figure 2). The operational assumption would be that the reactor system would be preheated to $330{ }^{\circ} \mathrm{C}$ during start-up phase, however, at steady state conditions, $237{ }^{\circ} \mathrm{C}$ would be sufficient for the reactor to self-sustain the required outlet conditions. The recuperator outlet is then fed into the HTL reactor through a tubular jacket circulating the "reaction chamber" in the center of the envisaged reactor, as shown in Figure 2. The reactor design, inspired by the cooled wall supercritical water oxidation reactor developed by the University of Valladolid [39], was envisaged to exploit and recover the exothermic heat of lignocellulose degradation under hydrothermal condition. Ibbet and his colleagues [40] reported that hydrothermal degradation below the critical point of water, at acidic conditions present by water dissociation, initiates exothermic heat $\left(\Delta Q_{\text {degradation }}\right)$ around $180^{\circ} \mathrm{C}$ and peaks beyond $220^{\circ} \mathrm{C}$, which falls in line with our simulation findings.

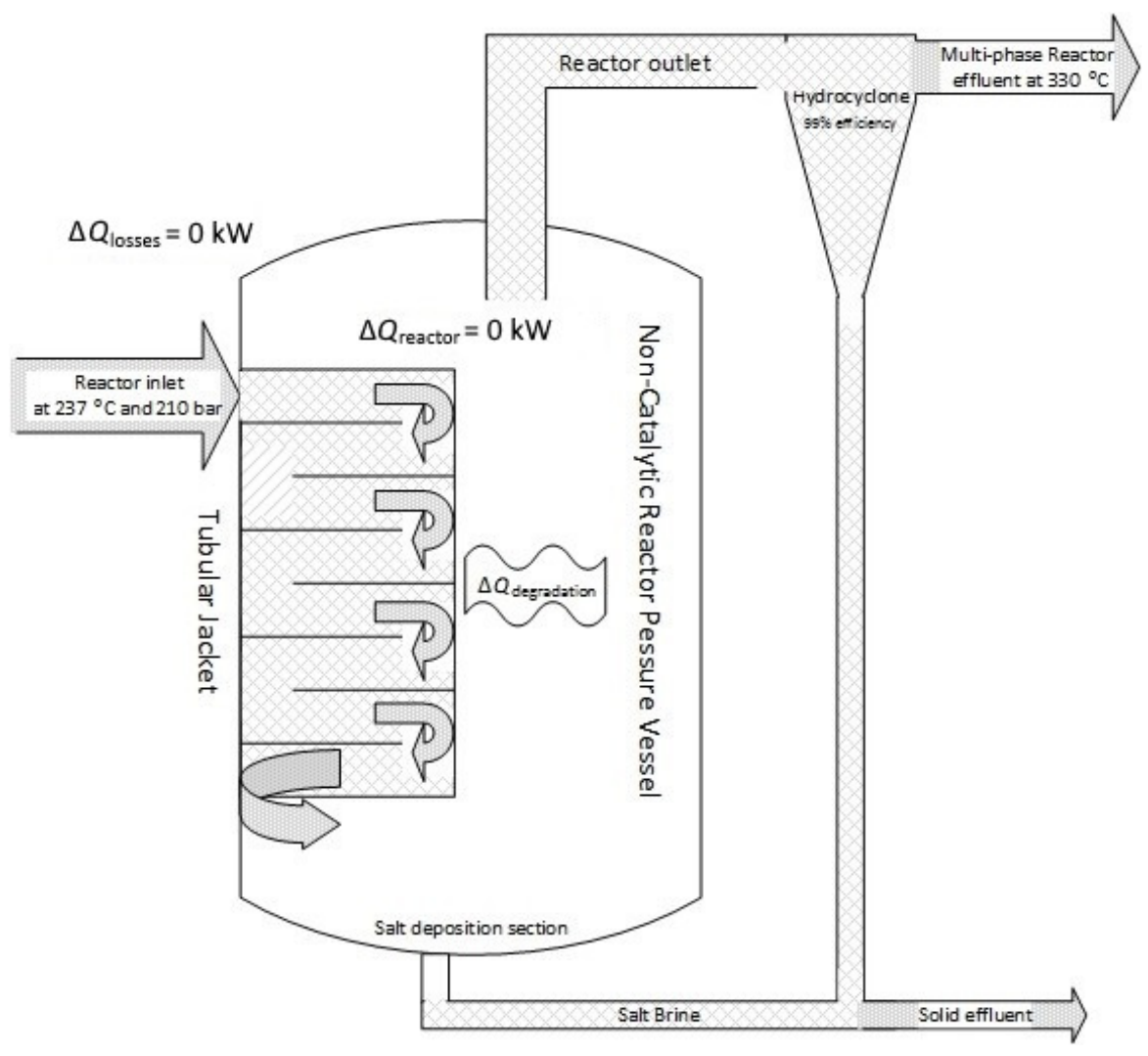

Figure 2. Schematic of the conceptual liquefaction reactor design 
The reactor outlet is then fed through a hydro-cyclone, with gross separation efficiencies up to $99 \%$ for the expected dense particles in the product slurry [41]. Two additional thermal assumptions for the reactor simulation were near perfect insulation with no losses to the environment or the reactor walls $\left(\Delta Q_{\text {losses }}\right)$ and the other is the complete recovery of ash with the solid char either in the hydro-cyclone or through flushing of the reactor vessel to collect disposed salts on the reactor wall as brine. The ash/inorganic recovery is justified based on the findings of experimental runs in [42], that showed for a lignocellulose feedstock, inorganics partition mostly either to solid or aqueous products, rather than the Biocrude. The chemical conversion itself was simulated with the built-in Aspen RYIELD reactor block. The predicted product composition for the multi-phase product was specified based on the findings from the LP model. The net exothermic heat, calculated on basis of heat of formation from the solid feedstock, was recycled by a thermal stream, INTERNAL to a preheater, AUXPRHT, which represented the tubular jacket of the reactor, as shown in Figure 2. Finally, the built-in Aspen Plus ${ }^{\circledR}$ iterative Designspec controller for the recuperator outlet temperature insured that the combined reactor-preheater model represented the envisaged operation of the reactor system, with an inlet at $237{ }^{\circ} \mathrm{C}$ and adiabatic conditions.

The hydro-cyclone outlet/HTL product stream then enters a two stage cooling and depressurizing, first through the recuperator and then through a combined throttle-auxiliary cooler system to reach $25^{\circ} \mathrm{C}$ and 18 bar. The target conditions were set based on a sensitivity analysis to minimize organic losses (gas or liquid) within the aqueous waste stream and maximize the light crude extracted due to phase equilibria in the following decanter unit, PRODSEP. In Figure 1, the stream throttling effect comes before the cooler, to minimize the auxiliary cooling load. While for cases where a district heating production unit is integrated, added after the recuperator, the throttling effect is subsequent to the coolers, to utilize the available thermal energy at elevated conditions. For the case with integrated power production, the liquid expander is located before the recuperator, which lowers the cold side outlet temperature below $237^{\circ} \mathrm{C}$. As such, an auxiliary preheater is added, driven by adiabatic heat from the downstream Steam Cycle (SC) boiler.

After the decanter, significant organic and inorganic content remains in the aqueous phase (in our case around 54\% on carbon basis) due to the higher miscibility of oxygenated compounds and carbon dioxide at such conditions. Several treatment methods to enhance carbon recovery have received attention in literature for the aqueous yield such as recirculation, anaerobic digestion, condensed phase ketonization and subsequent gasification, all of which have shown various opportunities and drawbacks [43]. A more direct recovery/upgrading approach is the separation of the organic content through mechanical or thermal separation technologies. Ramirez et al. [27] reviewed different separation technologies for HTL Biocrude and other technologies previously applied for pyrolysis bio-oil upgrading, most of which remain in lab or pilot scale operation. Solvent extraction remains one of the most technically feasible approaches due to the wide application in the petrochemical industry. Aside from the direct product extraction function, the use of solvent reportedly leads to stabilizing the chemical composition of the Biocrude also, by scavenging on unsaturated organics [15]. Several organic solvents proposed in literature showed relatively effective recovery of the dissolved organics, where the highest reported yields for lignocellulose feed were around $34 \%$. In the simulation, the extraction process is simulated as a two-step separation, first a flash drum to reduce stream pressure to ambient condition and release the dissolved $\mathrm{CO}_{2}$, followed by a standard solvent separator of the heavy crude from the aqueous stream. The solvent separator is simulated to mimic the results of an organic solvent extraction system developed in [44]. 


\section{The combined heat and power simulation model on Aspen Plus ${ }^{\circledR}$}

The employed SC for CHP production is based on a reference base case for biomass-fueled power plants, reported in earlier work in our research group [29]. The CHP plant includes 15 main components, shown in Figure 3. The main design considerations are both the live steam conditions, at $510{ }^{\circ} \mathrm{C}$ and $60 \mathrm{bar}$, for power extraction and a set DHN load at 16.5 MW, with a return and outgoing temperature conditions of 83 and $110^{\circ} \mathrm{C}$, for full load operations. The $16.5 \mathrm{MW}$ design value for the DHN is set as a constraint in the study because the value represents $60 \%$ of the maximum heat demand occurring in the DHN, a typical design value for Nordic DHNs [35].

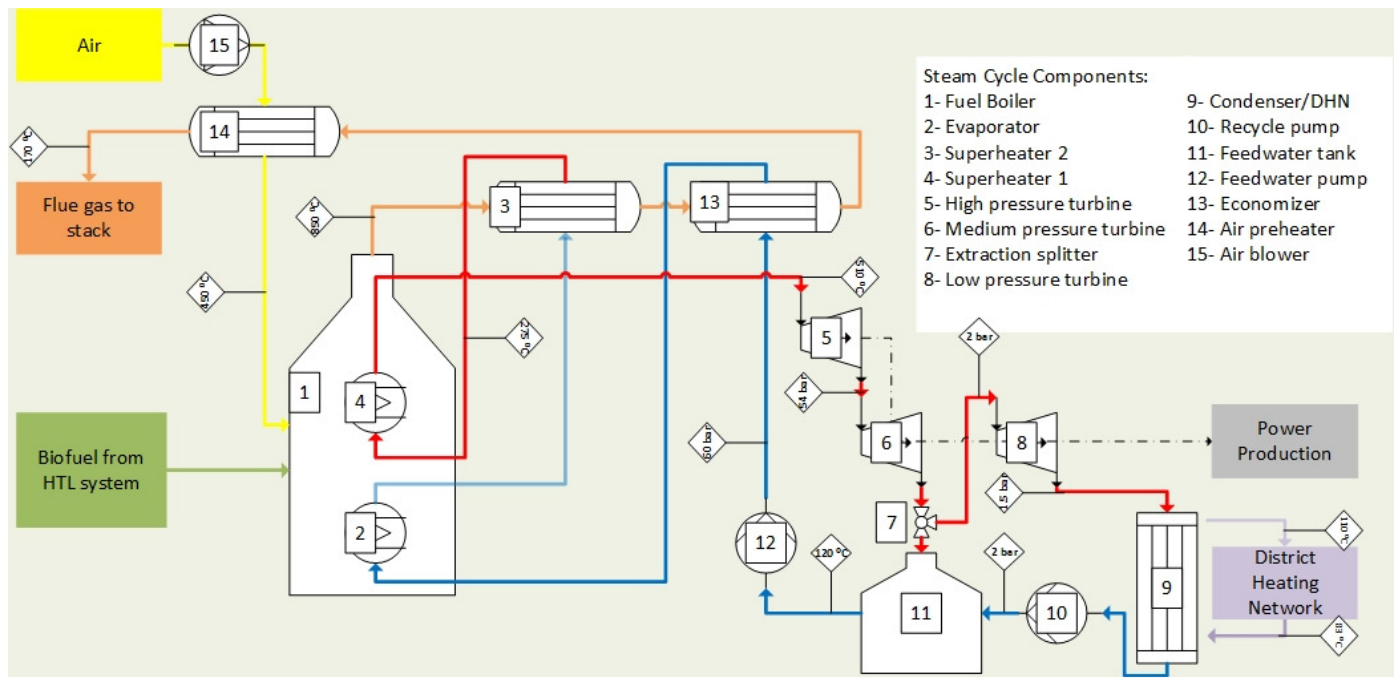

Figure 3. Schematic of the simulated steam cycle, identifiers for components and design conditions are included

The fuel boiler is a Bubbling Fluidized Bed (BFB) type, utilized commercially for small-scaled biomass-fueled power plants in Finland [45]. The boiler (unit No. 1 in Figure 3) is simulated as a standard RGibbs reactor in Aspen Plus, with the air flow controlled to maintain oxygen content in the flue gas at $6 \mathrm{wt} . \%$ dry basis. The evaporator (No. 2) and second superheater (No. 4) units utilize the adiabatic heat within the boiler. While the first superheater (No. 3), the economizer (No. 13) and the air preheater (No. 14) utilize the flue gas leaving the boiler at $850{ }^{\circ} \mathrm{C}$ in a cascading order. The heat exchanger design arrangement and the mass flow of the $\mathrm{SC}$, simulated as a variable for each case, control the flue gas outlet to the stack between $170-180{ }^{\circ} \mathrm{C}$ at full load conditions. This is to maintain part-load operation temperature at a minimum of $120^{\circ} \mathrm{C}$ [29] (part load operation is not modelled in this study). Another set design consideration is the multi-stage turbine system, where the high-pressure turbine (No. 5) acts as a regulation stage at 60 bar, the medium pressure turbine (No. 6) inlet and outlet conditions are set at 58 and 2 bar respectively. The extraction splitter (No. 7) maintains the feedwater preheater temperature of $120{ }^{\circ} \mathrm{C}$, while the last turbine (No. 8) outlet conditions is set at 1.55 bar. The SC design considerations are similar for all investigated cases, the only changes are for the case with integrated power production in the HTL system. In order to accommodate partitioning some of the boiler adiabatic heat for the auxiliary preheater, AUXPRHT in HTL reactor system, the flue gas temperature to the stack was relaxed to $200{ }^{\circ} \mathrm{C}$.

\section{Studied integration cases}

Table 3 describes the distinctive differences between the case studies considered in this study. The reference case is $100 \%$ CHP, which represents the combustion of the 
forest residue feedstock in the fuel boiler of the CHP system directly. All other cases employ the HTL reactor system as a fuel upgrading step, while differ on the utilization of the HTL yield or the integrated CHP operation (electricity and district heat production from the HTL waste heat along with the CHP plant). For the plant feedstock, cases 1-6 had the DHN network load of 16.5 MW set as a constraint, while the inlet flowrate remained a variable. While for quantitate comparison, case 7 had a similar flow rate for that of the 100\% CHP case. The design considerations in the CHP plant were similar for all cases, except for case 7, as explained in the earlier section.

Table 3. Comparison between the different study cases [Steam Cycle (SC), Electricity (E) and District Heat (DH)]

\begin{tabular}{|c|c|c|c|c|}
\hline Case & SC fuel & Products & Waste streams & CHP design \\
\hline $100 \% \mathrm{CHP}$ & Forest residue & $\mathrm{CHP}$ & N/A & SC only \\
\hline 1 & HTL Biocrude & CHP & $\begin{array}{l}\text { HTL aqueous, } \\
\text { solid \& gas }\end{array}$ & SC only \\
\hline 2 & HTL Biocrude \& solid & CHP & HTL aqueous \& gas & SC only \\
\hline 3 & $\begin{array}{l}\text { HTL Biocrude, } \\
\text { solid \& gas }\end{array}$ & CHP & HTL aqueous & SC only \\
\hline 4 & HTL solid \& gas & $\begin{array}{l}\text { Biocrude \& } \\
\text { CHP }\end{array}$ & HTL aqueous & SC only \\
\hline 5 & HTL solid \& gas & $\begin{array}{l}\text { Biocrude \& } \\
\text { CHP }\end{array}$ & HTL aqueous & $\begin{array}{l}\text { SC \& DH } \\
\text { from HTL }\end{array}$ \\
\hline 6 & HTL solid \& gas & $\begin{array}{l}\text { Biocrude \& } \\
\quad \text { CHP }\end{array}$ & HTL aqueous & $\begin{array}{l}\text { SC, DH \& E } \\
\text { from HTL }\end{array}$ \\
\hline 7 & HTL solid \& gas & $\begin{array}{l}\text { Biocrude \& } \\
\text { CHP }\end{array}$ & HTL aqueous & $\begin{array}{l}\text { SC, DH \& E } \\
\text { from HTL }\end{array}$ \\
\hline
\end{tabular}

Cases 1-4, consider the HTL reactor system as a chemical fuel-upgrading step only without integrated electricity and district heat production from the HTL waste heat (in replacement to the cooling utility). Cases 5-7 investigate the contribution of the integrated CHP within the HTL system on the overall efficiency. Case 5 includes a DHN cooler for the HTL yield, while cases 6-7 include a liquid expander along with the DHN cooler. Cases 1-3 compare the contribution of each HTL product through direct combustion on the overall efficiency of CHP operation. While case 4, shows the influence of decoupling Biocrude production from CHP production, for other end-user utilization, e.g. as marine fuel oil or as feed to transportation fuels upgrading units (the end user utilization beyond CHP is outside of the current scope of analysis). In other words, for case 4 along with cases 5-7, only solid and gas yield are combusted in the CHP fuel boiler. The operational assumption here, a Circulating Fluidized Bed (CFB) operates as a char combustor for the HTL solid yield. The selection of the CFB configuration is based on similar synergies to those associated with biomass pre-treatment systems integrated with CFB boiler systems [29]. The extracted sand (as fluidizing medium) from the CFB acts as a heat transfer medium for auxiliary pre-heaters adapted in the HTL system, as is the configuration in case 7 , similar configurations have been adapted in literature [46]. While a fuel gas burner utilizes the sweetgas produced, after $\mathrm{CO}_{2}$ and sulphur gases removal with an amine scrubber system from the gas yield.

The thermal efficiency for the different cases are evaluated on Lower Heating Value (LHV) basis of forest residue plant input, as shown in eq. (1):

$$
\text { Overall efficiency }=\frac{W_{\text {net }_{\text {power }}}+Q_{\text {net }_{\text {DHN }}}+Q_{\text {biofuels }_{\text {LHV }}}-W_{\text {pretreatment }}}{Q_{\text {fuel }_{\text {LHV }}}}
$$


where $W_{\text {net }_{\text {power }}}$ is the net electricity production, $Q_{\text {net }_{\text {DHN }}}$ is the district heat production, $Q_{\text {biofuels }_{\text {LHV }}}$ is the net HTL Biocrude product on LHV basis, $W_{\text {pretretment }}$ is the power consumption of the coarse chipping pre-treatment unit and $Q_{\text {fuel }}{ }_{\mathrm{LHV}}$ represents the plant feed.

\section{Techno-economic assessment}

The TEA attempts to scrutinize the different cases with economic indicators to establish feasibility and commerciality of the integration scenarios. The TEA defines the minimum selling price of the final bio-products (Biocrude, electricity and district heat) for each case study investigated, taking into account capital and operational costs over a plant lifetime of 20 years. The Total Capital Investment (TCI) estimation followed that reported by Bejan and Tsatsaronis [19] and was based on the $n^{\text {th }}$ plant assumption. Contingency costs (10\% of total capital investment) were considered, however costs associated with the first of its kind plant were not accounted for. The TCI is estimated as the sum of the Purchase Equipment Cost (PEC) of the plant processing units, multiplied by an installation factor and a PEC to TCI ratio to account for other direct and indirect costs associated with the plant. The PEC costs are based on reports in literature or by the Aspen Plus ${ }^{\circledR}$ economic analyzer tool, all assumptions and estimations related to the TCI are detailed in Table 4. It is worth to mention that, all PEC estimation here, adapted the upper limits reported in literature to ascertain that the assessment did not underestimate related purchasing costs. The sizing and scaling for the PEC of each process unit in each case study was according to eq. (2). Scaling factors- $\alpha$ of 0.6-0.8 were adapted for all components and the Chemical Engineering Plant Cost Indices (CEPCI) was used to account for 2016, the base year of the current study. Other capital assumptions worth to mention are the $100 \%$ equity basis, with no carry over debt and no salvage value for the plant components at the end of the operational lifetime:

$$
\text { Compenent cost }=\mathrm{PEC}_{\text {ref }}\left(\frac{\mathrm{CEPCI}_{2016}}{\mathrm{CEPCI}_{\text {ref }}}\right)\left(\frac{\text { Capacity }_{\text {case study }}}{\text { Capacity }_{\text {ref }}}\right)^{\alpha}
$$

The Operation and Maintenance (O\&M) cost consisted of fixed and variable costs. Fixed operational costs included employee salaries and benefits, overhead, maintenance and insurance. The plant personnel was estimated to be 15 employees for the CHP plant operation. For the integrated cases the staff size was assumed to be 20 at least and 30 for the case with the highest feedstock throughput. Cases with lower feedstock throughput were estimated by a linear correlation relative to the plant capacity $(20+$ capacity/highest capacity) and rounded up to the next full number. The staff members were estimated to have an averaged $36 \mathrm{k}$ EUR annual salary and a 50\% and 30\% overhead and insurance factors respectively, as recommended in [19]. Variable costs were dependent on the annual operational time, set at 8,000 hours. It included purchased material streams such as feedstock, process water (a 10\% make up fraction as an assumption), organic solvent and amine make up streams, along with waste disposal streams for solid or gas (if present in the study case) and aqueous (post the waste water treatment facility). The escalation rate for the O\&M costs was set at 3\%. While for the feedstock, the pre-tax market price fluctuations of wood chips in the Finnish market between years 2002-2016 were the basis of estimation. The minimum selling price of the product Biocrude in the poly-generation cases is a function of the price of the co-products, electricity and district heat, estimated similar to the feedstock, as shown in Figure 4. The Net Present Value (NPV) of the plant was determined based on the discounted cash flow of the plant over the 20-year lifetime (construction period costs rolled to first operational year). For NPV value calculations, the market price for heavy fuel oil was used as an indicator for the Biocrude market value, 
shown also in Figure 4. Finally, a sensitivity analysis was conducted, with the Principal Component Analysis (PCA) method, for both Biocrude minimum selling price and plant NPV to establish the influence of the price assumptions applied, with a bandwidth of $0-5 \%$ escalation rate for each of the four material prices estimated from Figure 4.

Table 4. TCI estimation assumption for the case studies

\begin{tabular}{|c|c|c|c|}
\hline Unit & Ref. & $\begin{array}{l}\text { Cost per ref. } \\
\text { capacity }\end{array}$ & $\begin{array}{l}\text { Year of } \\
\text { ref. }\end{array}$ \\
\hline HTL system & & & \\
\hline $\begin{array}{c}\text { (pre-treatment unit }+ \text { feed pump }+ \text { recuperator }+ \\
\text { auxiliary heater and cooler }+ \text { reactor vessel }+ \\
\text { solid separator }+ \text { decanter) }\end{array}$ & {$[47]$} & $\begin{array}{l}2.3 \mathrm{M} \text { EUR per kg } \\
\text { of solid feed }\end{array}$ & 2007 \\
\hline Solvent extractor system & {$[44]$} & $\begin{array}{l}0.11 \mathrm{M} \text { EUR per } \mathrm{kg} \\
\text { of aqueous yield }\end{array}$ & 2015 \\
\hline $\begin{array}{c}\text { HTL }- \text { Liquid expander } \\
\text { (estimated based on pump costs) }\end{array}$ & {$[36]$} & $\begin{array}{l}0.22 \text { M EUR per kg } \\
\text { of solid feed }\end{array}$ & 2012 \\
\hline HTL - district heat exchanger & $\begin{array}{l}\text { Aspen } \\
\text { Plus }{ }^{\circledR}\end{array}$ & & \\
\hline Acid gas removal unit & [48] & $\begin{array}{l}0.18 \text { M EUR per kg } \\
\text { of gas yield }\end{array}$ & 2005 \\
\hline Boilers and SC components & [29] & $\begin{array}{l}0.93 \text { M EUR per } \\
\text { MW of solid feed }\end{array}$ & $2016^{*}$ \\
\hline Waste water treatment facility & [49] & $\begin{array}{l}0.29 \mathrm{M} \text { EUR per } \\
\text { litre of } \\
\text { aqueous yield }\end{array}$ & 2016 \\
\hline Installation factor & {$[50]$} & $20 \%$ & \\
\hline Equipment capital investment factor ${ }^{* *}$ & [19] & $35 \%$ & \\
\hline Contingency & {$[50]$} & $10 \%$ & \\
\hline Effective rate of return on investment & & $10 \%$ (estimated) & \\
\hline
\end{tabular}

${ }^{*}$ The cost of the boiler and SC components is from data obtained from a Finnish biomass fired power plant, used for the $100 \%$ CHP case and scaled for the other cases

${ }^{* *}$ PEC percentage relative to TCI

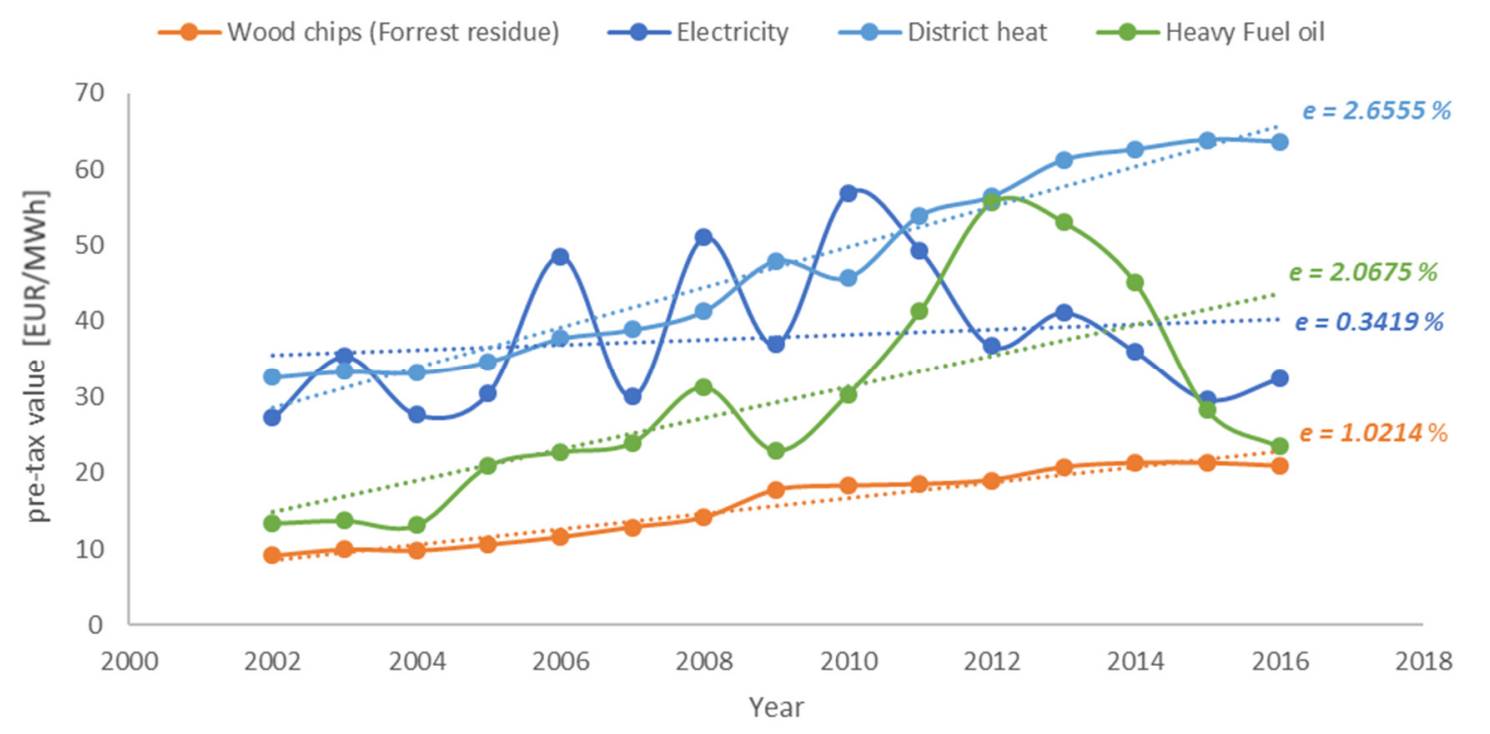

Figure 4. Estimated escalation rate (e) for material and energy stream costs based on price fluctuations in the Finland between years, 2002 and 2016 (data obtained from discussions with stakeholders and [51]) 


\section{RESULTS}

The study findings are reported and discussed in the following structure:

- Simulation results and validation for the developed HTL thermo-chemical and reactor system model;

- Comparative assessment of the HTL-CHP integration scenarios, from both a thermal and economic perspective.

\section{Liquefaction reactor system}

The logic for the GAMS LP resource allocation model is to match the mass balance, while maximizing the solid feed conversion to organics (desirable products) and maintaining the specified minimum by-product yield (solid residue and gas) and maximum organic compounds yield (Biocrude quality). Figure 5 shows the distribution of the phase products from the model on carbon (a) and mass basis (b). Carbon recovery reached 59\% in the organics with a mass yield of $466 \mathrm{~g}$ per $\mathrm{kg}$ of dry solid feed. Carbon losses in solid residue and gases were 31 and 10\% respectively. Both solid and gas yields at 276 and $167 \mathrm{~g}$ per $\mathrm{kg}$ of dry solid feed are slightly higher than the constrained minimum values by the model. This is a result of the constrained organic compound yields. Logically organic production in general competes with solid and gas formation mechanisms from an elemental balance perspective. Also, in the HTL reactive conditions, the available free radicals in subcritical water allow for both the re-polymerization and cyclization of intermediates to yield solid, while at the same time promoting gas formation Bourdard reactions [14]. The elevated solid and gas yields along with a balance of $91 \mathrm{~g}$ of reactive water (not constrained by the model) enabled the matching of the mass balance. Reactive water in the model is not biomass based moisture (data in Figure 5 is on dry feed basis), but released water due to degradation mechanisms such as dehydration and condensation reactions [9]. Most of collected experimental samples in literature are dried for analytical requirements and as such, information on reactive water yield is limited in literature [27].

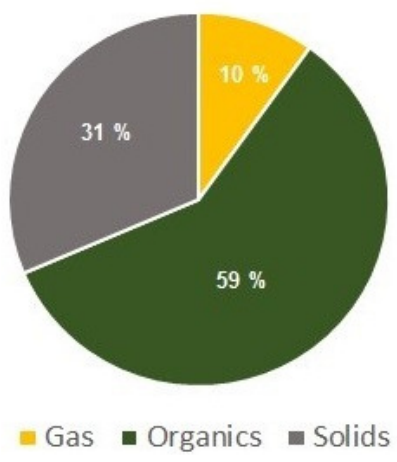

(a)

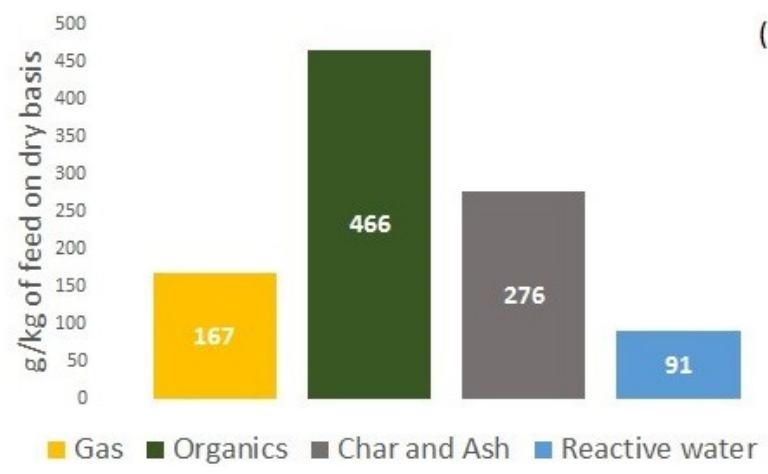

(b)

Figure 5. HTL reactor yield based on the predictive model at $330{ }^{\circ} \mathrm{C}$ and 210 bar, carbon partitioning to the multi-phase yield (a) and the specific yields on dry feedstock basis (b)

The detailed compound distribution of the organic yield is shown in Figure 6. The two most abundant compounds account for almost a third of the yield, Syringol and Guaiacol at 23 and 14 wt.\% respectively. Both compounds are lignin derivatives, where seven out of the top ten compounds are intermediates from lignin degradation mechanisms. This falls in line with reports in literature of phenolic and aromatic structures resistance for further degradation in non-catalytic conditions after the initiation of lignin hydrolysis reactions by subcritical water [52]. Cellulose and hemi-cellulose originated compounds were present at smaller quantities compared to their lignin counterparts. Most noteworthy are the products from acid-catalyzed treatment 
(by hydronium ions $\mathrm{H}_{3} \mathrm{O}^{+}$) of cellulose such as furfurals and organic acids [17]. All pre-specified compounds were present in the organic yields with only 10 compounds reporting concentrations below $0.01 \mathrm{wt}$.\%. It is worth to mention that nitrogen partitioned almost completely into inorganic form (simulated as ammonia), while sulphur remained attached in hetero form (simulated as 4-Isopropylthiophenol), similar to reports in [53].
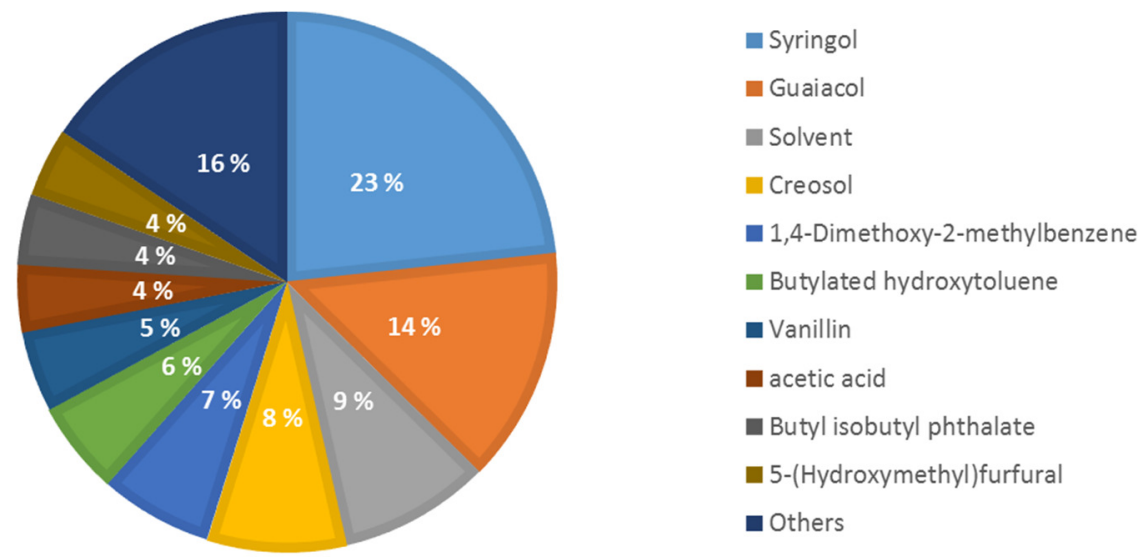

Figure 6. Product distribution in the HTL organic yield (none solid or gaseous products)

Figure 7 shows the carbon partitioning and mass yields of the Biocrude from the product recovery system, both at $28 \%$ and $221 \mathrm{~g}$ per $\mathrm{kg}$ of dry solids. The mass yield actually equates the median value $(22.0 \mathrm{wt} . \%)$ for Biocrude yield reported by Arturi et al. [18] for HTL experimental data in literature. Such fact does not offer a significant quantitative demonstration of our model, due to the distortion behind the wide experimental conditions examined in Arturi et al., however, it does present a qualitative validation of the reactor models ability to depict HTL experimental reports. A closer look show that the Biocrude mass yield matches that reported by [33] and is slightly higher (by 2 percentage points) than that of [31], two of the original datasets used to constraint the model. This validates the ability of the model's separator system to depict that of those specific experiments (both of which used organic solvent to maximize Biocrude yield). In a more general examination to validate model reliability, when compared to woody biomass experiments in [54] (not used to constraint the model), for non-catalytic processing conditions, the model matches the reported ranges. Also same could be said if the model is compared to the experimental data compiled in [6]. If compared to the earlier Figure 4 for the HTL reactor yield, it is observed that more than $50 \%$ of organic compounds have ended up in aqueous residue in the form water-soluble organics. This is attributed to the lower separation efficiency of the scrubber unit at $34 \%$. It is worth to mention that the extracted light crude, based on phase equilibria in the decanter, accounted to only $11 \%$ of the total Biocrude product.
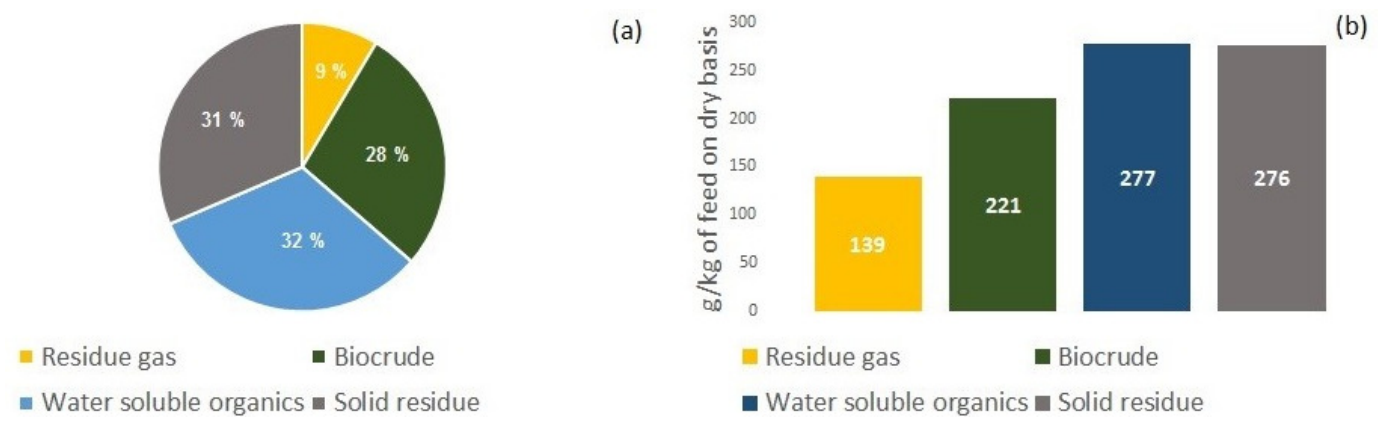

Figure 7. HTL yield after product recovery system, carbon partitioning to the multi-phase product (a) and product on dry basis (b) 
Table 5 shows a summary of the final elemental composition of the product Biocrude, and compares it with both the plant feedstock and reported Biocrude properties in literature. The influence of the HTL process on thermal quality upgrading is evident, as the oxygen content dropped from $41.4 \%$ on Dry Ash Free (DAF) basis in the feedstock to $30.7 \%$ in the Biocrude. As a result, the HHV increased from 20.2 and $9.96 \mathrm{MJ} / \mathrm{kg}$ on DAF and wet basis respectively to $27.6 \mathrm{MJ} / \mathrm{kg}$. It is also worth to mention that the HTL Biocrude elemental analysis (carbon and oxygen) at $330^{\circ} \mathrm{C}$ falls in between the reported range of non-catalytic experimental data at 300 and $350{ }^{\circ} \mathrm{C}$.

Table 5. Comparison between feedstock, HTL Biocrude and reported experimental data

\begin{tabular}{cccccc}
\hline & \multicolumn{2}{c}{ Feedstock DAF - Wet } & HTL Biocrude & \multicolumn{2}{c}{ [31] at 300-350 ${ }^{\circ} \mathrm{C}$} \\
\hline C [wt.\%] & 52.0 & 25.7 & 61.2 & 60.1 & 64.9 \\
H [wt.\%] & 6.2 & 3.1 & 8.0 & 7.0 & 7.5 \\
O [wt.\%] & 41.4 & 20.4 & 30.7 & 32.9 & 27.6 \\
S [wt.\%] & 0.4 & 0.2 & 0.1 & - & - \\
N [wt.\%] & 0.02 & 0.02 & 0.017 & - & - \\
Ash [wt.\%] & N/A & 0.7 & 0.0 & - & - \\
Moisture [wt.\%] & N/A & 50.0 & 7.7 & - & - \\
HHV [MJ/kg] & 20.19 & 9.96 & 27.58 & 24.38 & 27.74 \\
LHV [MJ/kg] & 18.84 & 8.07 & 25.54 & - & - \\
\hline
\end{tabular}

\section{Thermal analysis of the hydrothermal liquefaction-combined heat and power integration cases}

The modelling of the reference case (100\% CHP) and integrated cases (1-6) was constrained by the availability of a heat sink, the district heating network to replace the SC condenser duty in the relatively small-scaled CHP plants. As such, the $16.5 \mathrm{MW}$ DHN load was set for the cases and the plant fuel requirement was set as variable. Table 6 shows in detail the thermal performance for all cases, including case 7 were the plant feed was set similar to the $100 \%$ CHP plant and the DHN load set as a variable. The reference case thermal performance was $84.6 \%$ on LHV basis, with a net production of 5.6 MW electricity. The lower overall efficiency and net electricity production compared to a similar capacity biomass-fueled CHP plant at $87 \%$ and $6.1 \mathrm{MW}$ electricity respectively [45], is due to the elevated outlet pressure at the lower pressure turbine stage, 1.55 bar for our reference case compared to the standard $\sim 0.5$ bar. The elevated pressure is to maintain the condensation temperature in the DHN exchanger at $112{ }^{\circ} \mathrm{C}$.

Cases 1-3 investigate the influence of utilizing the different HTL yield products, Biocrude, solid and gas. The lower organic recovery of Biocrude in the HTL system at $34.7 \%$ on LHV basis, led plant fuel demand in case 1 to increase by $183 \%$ to $74 \mathrm{MW}$. The significant increase in fuel demand, led to a correlated increase in pre-treatment and pumping demand that dropped the net electricity production. Logically the overall thermal efficiency, was the lowest for case 1 (no gas and solid yield utilization) compared to all cases, at $26.1 \%$ only. The co-firing with solid residue (case 2) and with both solid residue and sweetgas yield (case 3), led to lower plant fuel demand, however remained higher than the reference case at 37 and $35.5 \mathrm{MW}$ respectively. The overall efficiencies were relatively higher at 56.3 and $58.9 \%$, almost two third of the reference case efficiency. This is attributed to the significant losses of organics in aqueous residue, as the total upgraded HTL yield utilized in case 3 accounted to only $74 \%$ of initial plant fuel on LHV basis.

As such, it could be concluded based on thermal modelling of cases 1-3, that for HTL to be employed as a feedstock upgrading technology, even if all multi-phase products considered (excluding water soluble organics), the thermal gains from upgrading the 
biomass feed do not offset direct combustion of wet biomass in a fuel boiler for CHP production. The process bottleneck remains the product recovery as higher Biocrude extraction efficiencies or valorization of the aqueous residue would allow HTL, as a simple fuel-upgrading step, to be more competitive thermally.

Table 6. CHP performance evaluators for the different cases, SC refers to the Rankine steam cycle, Net power, DHN and Biofuels refers to the Electricity, District heating network and Biocrude production respectively

\begin{tabular}{|c|c|c|c|c|c|c|c|c|}
\hline Cases & $\begin{array}{l}100 \% \\
\text { CHP }\end{array}$ & 1 & 2 & 3 & 4 & 5 & 6 & 7 \\
\hline Plant feed $\left[\mathrm{MW}_{\mathrm{LHV}}\right]$ & 26.15 & 74.02 & 37.01 & 35.53 & 68.10 & 33.85 & 34.25 & 26.15 \\
\hline Pre-treatment [MW] & 0 & 1.55 & 0.77 & 0.74 & 1.43 & 0.71 & 0.72 & 0.55 \\
\hline HTL Biocrude $\left[\mathrm{MW}_{\mathrm{LHV}}\right]$ & 0 & 25.71 & 12.86 & 12.34 & 23.66 & 11.76 & 11.89 & 9.11 \\
\hline HTL gas $\left[\mathrm{MW}_{\mathrm{LHV}}\right]$ & 0 & 2.17 & 1.09 & 1.04 & 1.99 & 0.993 & 0.988 & 0.757 \\
\hline HTL solid [MW $\left.{ }_{\text {LHV }}\right]$ & 0 & 26.78 & 13.39 & 12.86 & 24.64 & 12.25 & 12.39 & 9.495 \\
\hline Fuel in SC $\left[\mathrm{MW}_{\mathrm{LHV}}\right]$ & 26.15 & 25.71 & 26.25 & 26.24 & 26.64 & 13.24 & 13.38 & 10.25 \\
\hline Net biofuels [MW $\left.\mathrm{MHV}_{\mathrm{LHV}}\right]$ & 0 & 0 & 0 & 0 & 23.66 & 11.76 & 11.89 & 9.11 \\
\hline Net power prod. [MW] & 5.63 & 4.36 & 5.12 & 5.16 & 4.48 & 2.26 & 2.88 & 2.21 \\
\hline Net HTL power [MW] & 0 & -1.50 & -0.75 & -0.72 & -1.38 & -0.68 & 1.41 & 1.13 \\
\hline Net SC power [MW] & 5.63 & 5.86 & 5.87 & 5.88 & 5.86 & 2.95 & 1.39 & 1.07 \\
\hline Net DHN prod. [MW] & & & & 16.5 & & & & 12.13 \\
\hline Ratio from HTL [\%] & 0 & 0 & 0 & 0 & 0 & 50.3 & 76.2 & 75.0 \\
\hline Electrical eff. [\%] & 21.5 & 3.8 & 11.7 & 12.4 & 4.5 & 4.6 & 6.3 & 6.4 \\
\hline DHN eff. [\%] & 63.1 & 22.3 & 44.6 & 46.4 & 24.2 & 48.7 & 48.2 & 46.4 \\
\hline Biofuel conversion [\%] & 0 & 0 & 0 & 0 & 34.7 & 34.7 & 34.7 & 34.7 \\
\hline Overall eff. [\%] & 84.6 & 26.1 & 56.3 & 58.9 & 63.5 & 88.1 & 89.2 & 87.5 \\
\hline
\end{tabular}

Case 4 investigates the poly-generation of biofuels along with CHP production. The extracted Biocrude is assumed to be sold (at the gate) and transported for offsite utilization (e.g. as marine fuel), while both solid residue and sweetgas are combusted onsite in the fuel boiler of the SC. The plant fuel demand at $68 \mathrm{MW}$, increased by $91 \%$ compared to the onsite utilization case 3. While, the overall efficiency increased by almost $5 \%$ from $58.9 \%$ in case 3 to $63.5 \%$ for case 4 . The additional Biocrude product at 23.7 MW (34.7\%) was offset by the lower electrical (by $~ 7 \%$ ) and DHN efficiencies (by $21 \%$ ) with increased plant fuel. As such, case 4 shows that poly-generation concept presents additional biofuel production opportunity through HTL, albeit with a lower overall thermal performance than the reference direct combustion case.

Case 5-7 investigate integrated heat and power production from the HTL system along with the poly-generation of biofuel and downstream CHP. Both cases 5 and 6, had plant fuel demand higher than the reference case but recorded higher overall efficiencies at 88.1 and $89.2 \%$ respectively. The higher efficiencies are attributed to the exploitation of exothermic heat generated in the HTL reactor system for the production of CHP. In cases 1-4, such heat only added to the plant cooling utility. The elevated thermal conditions of the reactor outlet offset both the HTL preheating and pumping requirements and lead to net positive heat and power production. The higher fuel demand was in order to match the DHN load of the reference case. The introduction of liquid expansion at the HTL reactor outlet led to a hot utility pinch at the inlet conditions. As a result, plant fuel was slightly higher for case 6 over that of case 5 due to the accommodation of the auxiliary preheater demand in the HTL by the SC fuel boiler. Another effect by the introduction of the expander is that the HTL product cooling steps in the recuperator and DHN exchanger were at de-pressurized conditions, and as such, 
more heat was available for extraction. As such, the contribution to the DHN from the HTL system was at 50 and $76 \%$ for cases 5 and 6 respectively. The net electricity production was significantly lower for both cases compared to the reference case, due to the lower capacity of the SC.

Thus, it could be concluded that the introduction of direct heat and power generation in the HTL system would lead to enhanced thermal poly-generative performance compared to any of the cases studied. Case 7 offers a quantitative comparison of the integrated poly-generative configuration of products to the CHP only configuration of the reference case. The overall thermal efficiency increased from 84.6 to $87.5 \%$, while the additional biofuel product led to lower net power production by $49 \%$ and lower DHN production by $26.5 \%$. To offer a contextual valuation to the efficiency findings, if compared to the integrated pyrolysis-CHP cases reported in [46], where the overall thermal performance drops between 5.1 to $7.7 \%$ for the different pyrolysis scenarios proposed. The aqueous processing and exothermic nature for HTL case 7, which allow for the direct recovery to heat and power, add to the overall plant performance by $2.9 \%$. It is worth to mention that SC conditions differ between both studies, and the integration scenarios in [46] only consider utilization of excess pyrolysis heat for feedstock pre-treatment (drying), a net negative function. In earlier work reported by our group [29], for a similar pre-treatment function for the pyrolysis-CHP configuration, with a similar CHP design conditions to this study, the pyrolysis integration also reduced the plant thermal performance by $2.4 \%$. If the HTL-CHP integration is compared to other biofuel pathways integrated within CHP configurations, such as Bio-SNG, methanol or Fischer-Tropsch, with a thermal efficiency of 86,74 and $65 \%$ respectively [55], the same conclusion of superior thermal performance by the HTL integration concepts presented in this study could be drawn.

\section{Economic perspective}

Figure 8 shows the breakdown of the bio-product production costs for all integration scenarios compared to the reference $100 \%$ CHP case and a pyrolysis case with a similar feed capacity to the reference case. The production cost in Figure 7 is an average selling price for electricity, district heat and Biocrude (if present) based on the first law of thermodynamics (no distinction is given to the nature of MWh produced). In general, the HTL integration scenarios had an overall higher production cost (right y-axis) than the reference case and pyrolysis one. The varied production costs correlate to the overall efficiencies presented earlier in Table 6 for cases (1-4), with a lower efficiency leading to higher costs. However, for the integration cases (5-7) of DH and electricity production within the HTL system, the production cost show more favorable value for the integration of DH (case 5) at $88 \mathrm{EUR} / \mathrm{MWh}$ than the integration of both $\mathrm{DH}$ and power (cases 6 and 7) at 90 and 100 EUR/MWh respectively, despite the latter ones having a higher overall efficiency. This is mainly attributed to the increase of the Balance Of Plant (BOP) costs (which include the additional expander unit) by nearly +2 and +4 EUR/MWh for cases 6 and 7 respectively compared to case 5. This was not offset by a reduction in either the HTL system or the boiler and SC component costs due to the addition of the HTL auxiliary heater.

A general conclusion could be summarized, as, although the aqueous processing of biomass enables more recovery of energetic products than ambient thermochemical processes, such as direct combustion or pyrolysis, it remains significantly more costly of a process. In the present circumstances, the chemical upgrading function is insufficient to offer an additional economic benefit, while the costs associated with power production hinder it less favorable than the utilization of the elevated HTL thermal conditions for process heat production only. 
Figure 8. The production cost per MWh of bio-product and the cost contribution of major plant components (fuel cost: forest residue feedstock, fixed O\&M: personal, maintenance and insurance, variable cost: material operational cost excluding plant feedstock, HTL system: components based on Table 4, BOP: balance of plant, components not in the HTL system and boilers and CHP components, PP capital: total pyrolysis plant capital related costs)

Figure 8 also shows the contribution (relative \%) of other cost components in the plant, (left y-axis). It is worth to mention that all costs are levelized across the 20-year lifetime by both the Capital Recovery Factor (CRF) for capital related costs and the Constant Escalation Levelization Factor (CELF) for fixed and variable O\&M costs. Please refer to [19] for detailed derivation of each factor. Some results from the figure are summarized below:

- The highest contribution of feedstock cost was for the 100\% CHP reference case at $52 \%$, as is the case with conventional biomass fueled systems [29]. However, the absolute value, at 26.7 EUR/MWh, was only higher than the more efficient HTL-CHP integration scenarios (cases 5-7) by -2.8, -3.1 and -2.7 EUR/MWh respectively. This represents a considerable economic advantage of the integration scenarios (cases 5-7) as it reduces the influence of feedstock market price volatility on profitability;

- Fixed O\&M costs did not show significant changes between all cases, ranging between $12-18 \%$;

- Variable O\&M costs had only a significant contribution to case 1, where all HTL by-product streams were disposed and not valorized. Solvent, water make-up and cooling water costs (due to assumed feasible recycling) along with ash disposal cost proved insignificant (less than 1\%);

- The contribution of the HTL system (refer to Table 4 for components), was the largest capital related cost contribution, and almost matched the feedstock cost contribution. All cases had a similar contribution, falling in the range of $33.4 \%$ for case 1 and $36.3 \%$ for case 5 ;

- If compared to the total pyrolysis plant capital related costs, the HTL system cost alone (not considering BOP or boiler and SC components) remained higher. 
The production cost of pyrolysis plant at 64.5 EUR/MWh remained higher than the more efficient $100 \%$ CHP reference case at $50.8 \mathrm{EUR} / \mathrm{MWh}$, but was lower than the more efficient than both, HTL integration case 7 (similar feed capacity) at 99.7 EUR/MWh.

Table 7 shows a summary of the minimum selling price for Biocrude for all poly-generation cases under a set of market and capital assumptions. Biocrude defined as a novel product with no established market value, in contrast to the co-products of electricity and district heat, is set as a variable that takes on any additional production costs above the set market value for the co-products. In this analysis, the feedstock and the HTL system, both of which account for two thirds of production cost (refer to Figure 8) along with the co-product prices are varied and the Biocrude price is reported for worst, present and best -case scenario. For the present scenario, where the escalation rates are set according to present conditions shown in Figure 4 earlier, the lowest Biocrude selling price was for case 4 at 138 and 118 EUR/MWh for $100 \%$ and $70 \%$ HTL-PEC cost respectively. This is mainly attributed to the higher net power production for case 4 compared to the other cases (refer to Table 6) at the set district heating sink of 16 MW. However, for the best-case scenario (reduced feedstock and increased co-products escalation), case 4 had a lower minimum selling price only for the $100 \%$ HTL capital cost assumption. While, under a reduced HTL-PEC by $30 \%$ (and as a result an increased contribution of the fuel cost), case 5, which utilizes almost half of the feedstock capacity case 4 requires (refer to Table 6), has the lowest minimum selling price at 98.5 EUR/MWh.

Table 7. Comparison of the Biocrude minimum selling price for the poly-generation study cases under Best-case Scenario (BS), Present Scenario (PS) and Worst-case Scenario (WS), the difference in scenarios are the varied escalation rates for material stream prices [Feedstock (F), Electricity (E) and District Heat (DH)] minimum Biocrude selling prices are shown for each case under two assumptions, HTL system purchase equipment cost based on

Table 4 and under a reduced value by $30 \%$

\begin{tabular}{|c|c|c|c|c|c|c|c|c|}
\hline & & & \multicolumn{6}{|c|}{ Biocrude minimum selling price [EUR per MWh] } \\
\hline & $\begin{array}{l}\text { Escalation } \\
\text { rates }\end{array}$ & $\begin{array}{c}\text { Price } \\
\text { [EUR/MWh] }\end{array}$ & $\begin{array}{l}\text { HTL } \\
\text { PEC }\end{array}$ & 4 & 5 & 6 & 7 & Pyrolysis \\
\hline \multirow{3}{*}{ BS } & $\mathrm{F}(0 \%)$ & 20.9 & $100 \%$ & 124.0 & 125.3 & 132.7 & 156.4 & 68.7 \\
\hline & E $(5 \%)$ & 48.4 & $70 \%$ & 103.8 & 98.5 & 106.0 & 126.8 & 68.7 \\
\hline & $\mathrm{DH}(5 \%)$ & 66.6 & Diff. & $16 \%$ & $21 \%$ & $20 \%$ & $19 \%$ & $0 \%$ \\
\hline \multirow{3}{*}{ PS } & $\mathrm{F}(1.02 \%)$ & 22.6 & $100 \%$ & 138.2 & 146.9 & 154.8 & 177.9 & 85.4 \\
\hline & $\mathrm{E}(0.34 \%)$ & 33.3 & $70 \%$ & 117.9 & 120.1 & 128.1 & 148.3 & 85.4 \\
\hline & $\mathrm{DH}(2.66 \%)$ & 54.8 & Diff. & $15 \%$ & $18 \%$ & $17 \%$ & $17 \%$ & $0 \%$ \\
\hline \multirow{3}{*}{ WS } & $\mathrm{F}(5 \%)$ & 31.2 & $100 \%$ & 166.7 & 181.8 & 189.6 & 212.2 & 114.0 \\
\hline & E (0\%) & 32.4 & $70 \%$ & 146.4 & 155.0 & 163.0 & 182.6 & 114.0 \\
\hline & $\mathrm{DH}(0 \%)$ & 44.6 & Diff. & $12 \%$ & $15 \%$ & $14 \%$ & $14 \%$ & $0 \%$ \\
\hline
\end{tabular}

Figure 9 shows the result of a sensitivity analysis with the PCA method to quantify the influence of production cost contributors on the minimum selling price of Biocrude. Logically feedstock, HTL capital and other factors (include remaining capital and O\&M costs) lead to Biocrude price increase (positive variance in Figure 8), in contrast to the co-products price variance. The larger influence of the district heat over that of the electricity price is attributed to the lower power to heat ratios for the cases investigated (4-7) compared to the $100 \% \mathrm{CHP}$ case. It is worth to note that a change of one unit price for district heat could offset a similar one-unit price change of feedstock by a ratio greater than 1.5 for the more efficient cases (5-7). A favorable condition for cases with an abundancy of forestry and demand for district heat, such as the Nordic conditions. 


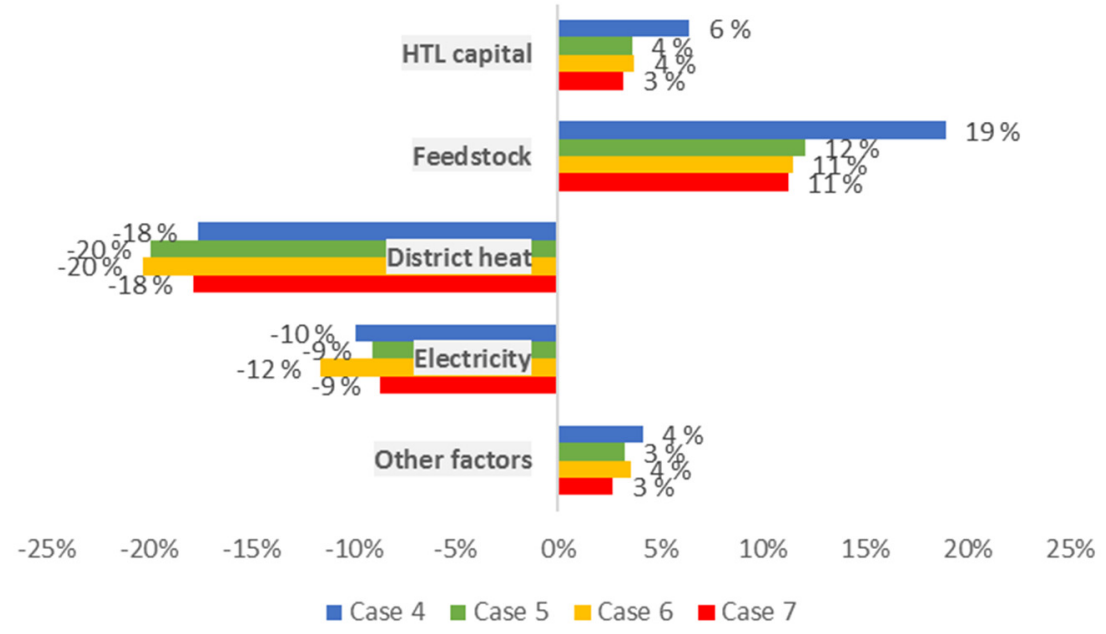

Figure 9. The influence (co-variance effect) on the minimum selling price of Biocrude, for a bandwidth of 0 to $5 \%$ escalation rate over the 20 years lifetime for each of feedstock, district heat and electricity and a $30 \%$ reduction of HTL capital

Heavy fuel oil is the closest fossil synonymous product to the HTL Biocrude or pyrolysis oil, and as such, market prices for heavy fuel oil (without environmental taxes) were used to project the market value of Biocrude. Table 8 shows a summary of NPVs for all cases investigated. The low projected Biocrude price, as well as the current low electricity market prices hinder the profitability of all cases (values in Table 8 shown in red). The direct combustion of the forest residue feedstock showed a viable and profitable operation only under a best-case scenario where feedstock prices remain constant and the coproduct prices increase all by an escalation rate of $5 \%$ over the project lifetime. Case 5 showed the most favorable conditions among the HTL integration scenarios at a NPV of -54.3 million EUR in the best-case scenario. Another perspective to read the tabulated values would be that for case 5 to break-even across the best-case scenario of the plant lifetime, subsidies and carbon credits that amount for 54.3 million EUR would be needed. For the present day scenario, if the $100 \%$ CHP reference case is compared to the similar feed capacity HTL case 7 and pyrolysis plant, 3.9, 84.8 and 51.3 million EUR would be needed for each respectively.

Table 8. Comparison of all investigated study cases NPV under Best-case Scenario (BS), Present Scenario (PS) and Worst-case Scenario (WS), the difference in scenarios are the varied escalation rates for material stream prices [Feedstock $(F)$, Electricity $(E)$, District Heat $(\mathrm{DH})$ and

Biocrude (B)] NPVs are shown for each case under two assumptions, HTL system purchase equipment cost based on estimated values in Table 4 and under a reduced value by $30 \%$, red highlight is for negative and green for positive NPVs respectively

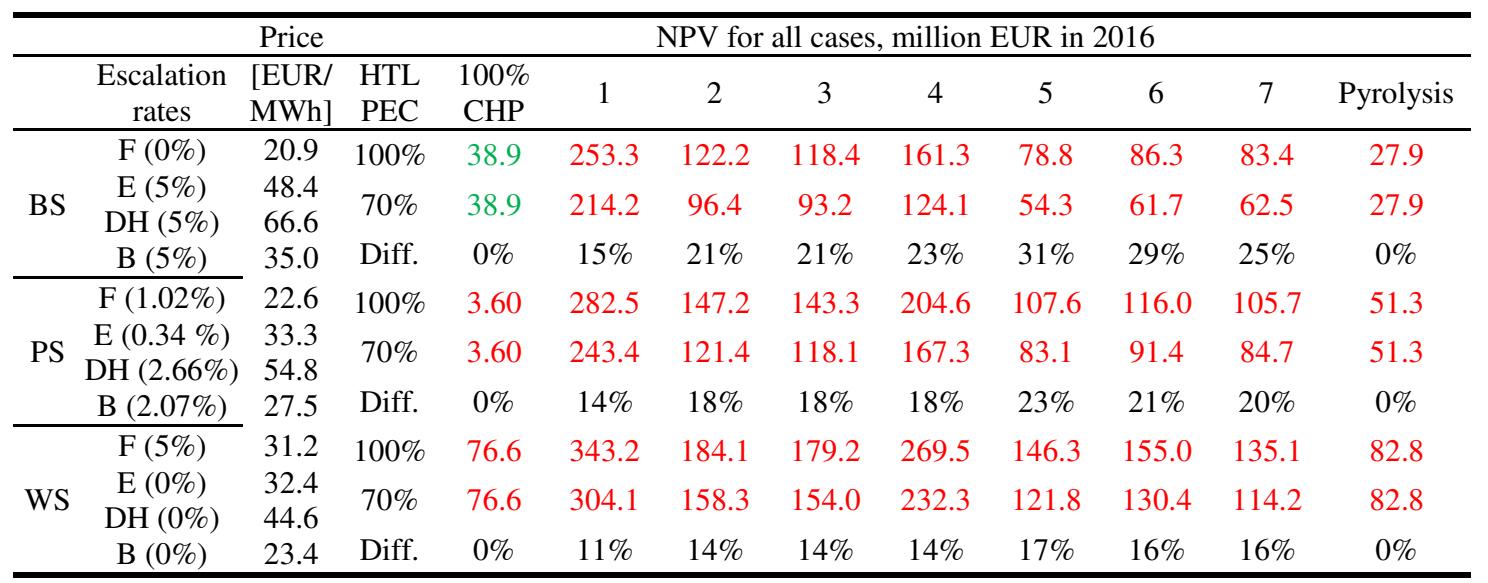


Finally, it is worth to mention that the material stream prices and the subsequent NPVs generated in this study do not consider any emissions abatement mechanisms such as the double credit biofuel incentives (which accounts for the waste nature of the feedstock and $\mathrm{CO}_{2}$-mitigation nature of the energy products, as is the case in our study). Such mechanisms are expected to be activated within the EU during the projected plant lifetime applied in this study. A development that would lead to significant reduction to the minimum Biocrude selling price and more feasible projected NPVs for the HTL integration scenarios.

\section{CONCLUSIONS}

This study presented the techno-economic performance indicators and drivers for the integration of the hydrothermal liquefaction process with downstream combined heat and power production. A gate-to-gate layout for different integration scenarios were modelled on Aspen Plus ${ }^{\circledR}$ simulation software. The deployment of the non-catalytic liquefaction system, at $330{ }^{\circ} \mathrm{C}$ and 210 bar, as a single chemical fuel-upgrading step enhanced the thermo-physical properties of the primary Biocrude product. The calorific value of the Biocrude increased from $10 \mathrm{MJ} / \mathrm{kg}$ for the solid feedstock to $27.6 \mathrm{MJ} / \mathrm{kg}$, both on wet basis. However, the increased calorific value did not offset the simplicity of the direct combustion process, which recorded higher overall plant efficiencies, at $84.6 \%$. This is attributed to the significant organic losses found within the liquefaction by-product streams, a process bottleneck that was overcome through holistic on-site utilization of the liquefaction thermal and chemical waste. The highest thermal performance for the proposed HTL-CHP integrations was $89.2 \%$, on lower heating value basis. This was obtained through integrated district heat and power production from the liquefaction waste heat, accompanied with the poly-generative production of Biocrude for offsite utilization and downstream combined heat and power production fueled by the liquefaction solid and gas by-products.

The current low market price for the plant co-products, electricity and district heat, led to unfavorable economic conditions for all the integration scenarios as well as the direct combustion case. The lowest production cost was recorded for the poly-generative case with district heat production (but no power) from the liquefaction waste heat at 88 EUR per MWh. While, the lowest minimum Biocrude selling price was 138 EUR per MWh for the poly-generative case without integrated utilization of the liquefaction waste heat. Heavy fuel oil was considered the basis to project future Biocrude prices. A sensitivity analysis showed that for a best-case scenario over a plant life-time of 20 years, at which the costs of the liquefaction system capital were reduced by $30 \%$, the feedstock procurement remained the same and the price of the co-products escalated by $5 \%$, incentives in the value of 54 million EUR should be secured for the plant to breakeven. While a direct combustion plant would net 39 million EUR in profits.

\section{ACKNOWLEDGMENT}

The corresponding author would like to acknowledge the support and funding for his doctoral research from the School of Engineering Aalto University (Grant No. AALTOENG2016) and Fortum foundation - Fortumin Säätiö, (Grant No. 201600157).

\section{NOMENCLATURE}

\section{Abbreviations}

BFB

Bubbling Fluidized Bed

BOP

Balance Of Plant

CEPCI

Chemical Engineering Plant Cost Indices 


\begin{tabular}{ll}
\hline CFB & Circulating Fluidized Bed \\
CHP & Combined Heat and Power \\
CRF & Capital Recovery Factor \\
DHN & District-Heating Network \\
GAMS & General Algebraic Modelling System software \\
HTL & Hydrothermal Liquefaction \\
LHV & Lower Heating Value \\
LP & Linear Programming \\
NPV & Net Present Value \\
O\&M & Operation and Maintenance \\
PCA & Principal Component Analysis \\
PEC & Purchase Equipment Cost \\
PSRK & Predictive Soave Redlich Kwong \\
SC & Steam Cycle \\
TCI & Total Capital Investment \\
TEA & Techno-Economic Assessment
\end{tabular}

\section{REFERENCES}

1. Elliott, D. C., Biller, P., Ross, A. B., Schmidt, A. J. and Jones, S. B., Hydrothermal Liquefaction of Biomass: Developments from Batch to Continuous Process, Bioresour. Technol., Vol. 178, pp 147-156, 2015, https://doi.org/10.1016/j.biortech.2014.09.132

2. Magdeldin, M., Kohl, T., De Blasio, C., Järvinen, M., Won Park, S. and Giudici, R., The BioSCWG Project: Understanding the Trade-Offs in the Process and Thermal Design of Hydrogen and Synthetic Natural Gas Production, Energies, Vol. 9, No. 10, p 838, 2016, https://doi.org/10.3390/en9100838

3. Toor, S. S., Rosendahl, L. and Rudolf, A., Hydrothermal Liquefaction of Biomass: A Review of Subcritical Water Technologies, Energy, Vol. 36, No. 5, pp 2328-2342, 2011, https://doi.org/10.1016/j.energy.2011.03.013

4. Peterson, A. A., Vogel, F., Lachance, R. P., Fröling, M., Antal, M. J. Jr. and Tester, J. W., Thermochemical Biofuel Production in Hydrothermal Media: A Review of Suband Supercritical Water Technologies, Energy Environ. Sci., Vol. 1, No. 1, pp 32-65, 2008, https://doi.org/10.1039/b810100k

5. Balat, M., Mechanisms of Thermochemical Biomass Conversion Processes, Part 3: Reactions of Liquefaction, Energy Sources Part A: Recovery Util. Environ. Eff., Vol. 30, No. 7, pp. 649-659, 2008, https://doi.org/10.1080/10407780600817592

6. Dimitriadis, A. and Bezergianni, S., Hydrothermal Liquefaction of Various Biomass and Waste Feedstocks for Biocrude Production: A State of the Art Review, Renew. Sustain. Energy Rev., Vol. 68, Part 1, pp 113-125, 2017, https://doi.org/10.1016/j.rser.2016.09.120

7. Jazrawi, C., Biller, P., Ross, A. B., Montoya, A., Maschmeyer, T. and Haynes, B. S., Pilot Plant Testing of Continuous Hydrothermal Liquefaction of Microalgae, Algal Res., Vol. 2, No. 3, pp 268-277, 2013, https://doi.org/10.1016/j.algal.2013.04.006

8. Jensen, C. U., Guerrero, J. K. R., Karatzos, S., Olofsson, G. and Iversen, S. B., Fundamentals of HydrofactionTM: Renewable Crude Oil from Woody Biomass, Biomass Convers. Biorefinery, pp 1-15, 2017.

9. Akiya, N. and Savage, P. E., Roles of Water for Chemical Reactions in High-Temperature Water, Chem. Rev., Vol. 102, No. 8, pp 2725-2750, 2002, https://doi.org/10.1021/cr000668w

10. Behrendt, F., Neubauer, Y., Oevermann, M., Wilmes, B. and Zobel, N., Direct Liquefaction of Biomass, Chem. Eng. Technol., Vol. 31, No. 5, pp 667-677, 2008, https://doi.org/10.1002/ceat.200800077 
11. Kruse, A. and Dahmen, N., Water - A Magic Solvent for Biomass Conversion, J. Supercrit. Fluids, Vol. 96, pp 36-45, 2015, https://doi.org/10.1016/j.supflu.2014.09.038

12. Gassner, M., Vogel, F., Heyen, G. and Maréchal, F., Optimal Process Design for the Polygeneration of SNG, Power and Heat by Hydrothermal Gasification of Waste Biomass: Thermo-Economic Process Modelling and Integration, Energy Environ. Sci., Vol. 4, No. 5, pp 1726-1741, 2011, https://doi.org/10.1039/c0ee00629g

13. Jarvis, J. M., Billing, J. M., Hallen, R. T., Schmidt, A. J. and Schaub, T. M., Hydrothermal Liquefaction Biocrude Compositions Compared to Petroleum Crude and Shale Oil, Energy Fuels, Vol. 31, No. 3, pp 2896-2906, 2017, https://doi.org/10.1021/acs.energyfuels.6b03022

14. Akhtar, J. and Amin, N. S., A Review on Process Conditions for Optimum Bio-Oil Yield in Hydrothermal Liquefaction of Biomass, Renew. Sustain. Energy Rev., Vol. 15, No. 3, pp 1615-1624, 2011, https://doi.org/10.1016/j.rser.2010.11.054

15. Tran, K. Q., Fast Hydrothermal Liquefaction for Production of Chemicals and Biofuels from Wet Biomass - The Need to Develop a Plug-Flow Reactor, Bioresour. Technol., Vol. 213, pp 327-332, 2016, https://doi.org/10.1016/j.biortech.2016.04.002

16. Yakaboylu, O., Harinck, J., Smit, K. G. and de Jong, W., Supercritical Water Gasification of Biomass: A Literature and Technology Overview, Energies, Vol. 8, No. 2, pp 859-894, 2015, https://doi.org/10.3390/en8020859

17. Fongarland, P., Essayem, N. and Rataboul, F., Noncatalyzed Liquefaction of Celluloses in Hydrothermal Conditions: Influence of Reactant Physicochemical Characteristics and Modeling Studies, Ind. Eng. Chem. Res., Vol. 56, No. 1, pp 126-134, 2017, https://doi.org/10.1021/acs.iecr.6b03846

18. Arturi, K. R., Strandgaard, M., Nielsen, R. P., Søgaard, E. G. and Maschietti, M., Hydrothermal Liquefaction of Lignin in near-Critical Water in a New Batch Reactor: Influence of Phenol and Temperature, J. Supercrit. Fluids, Vol. 123, pp 28-39, 2017, https://doi.org/10.1016/j.supflu.2016.12.015

19. Bejan, A. and Tsatsaronis, G., Thermal Design and Optimization, John Wiley \& Sons, NJ, USA, 1996.

20. Goudriaan, F. and Peferoen, D. G. R., Liquid Fuels from Biomass via a Hydrothermal Process, Chem. Eng. Sci., Vol. 45, No. 8, pp 2729-2734, 1990, https://doi.org/10.1016/0009-2509(90)80164-A

21. Zhu, Y., Biddy, M. J., Jones, S. B., Elliott, D. C. and Schmidt, A. J., Techno-Economic Analysis of Liquid Fuel Production from Woody Biomass via Hydrothermal Liquefaction (HTL) and Upgrading, Appl. Energy, Vol. 129, pp 384-394, 2014, https://doi.org/10.1016/j.apenergy.2014.03.053

22. Kumar, S., Lange, J.-P., Rossum, G. V. and Kersten, S. R. A., Liquefaction of Lignocellulose in Fractionated Light Bio-Oil: Proof of Concept and Techno-Economic assessment, ACS Sustain. Chem. Eng., Vol. 3, No. 9, pp 2271-2280, 2015, https://doi.org/10.1021/acssuschemeng.5b00547

23. Pearce, M., Shemfe, M. and Sansom, C., Techno-economic Analysis of Solar Integrated Hydrothermal Liquefaction of Microalgae, Appl. Energy, Vol. 166, pp 19-26, 2016, https://doi.org/10.1016/j.apenergy.2016.01.005

24. Hognon, C., Delrue, F. and Boissonnet, G., Energetic and Economic Evaluation of Chlamydomonas Reinhardtii Hydrothermal Liquefaction and Pyrolysis through Thermochemical Models, Energy, Vol. 93, Part 1, pp 31-40, 2015, https://doi.org/10.1016/j.energy.2015.09.021

25. Mahmood, R., Parshetti, G. K. and Balasubramanian, R., Energy, Exergy and Techno-economic analyses of Hydrothermal Oxidation of Food Waste to produce Hydro-char and Bio-oil, Energy, Vol. 102, pp 187-198, 2016, https://doi.org/10.1016/j.energy.2016.02.042

26. Summers, H. M., Ledbetter, R. N., McCurdy, A. T., Morgan, M. R., Seefeldt, L. C., Jena, U., Kent Hoekman, S. and Quinn, J. C., Techno-economic Feasibility and Life 
Cycle assessment of Dairy Effluent to Renewable Diesel via Hydrothermal Liquefaction, Bioresour. Technol., Vol. 196, pp 431-440, 2015, https://doi.org/10.1016/j.biortech.2015.07.077

27. Ramirez, J. A., Brown, R. J. and Rainey, T. J., A Review of Hydrothermal Liquefaction Bio-crude properties and prospects for upgrading to Transportation Fuels, Energies, Vol. 8, No. 7, pp 6765-6794, 2015, https://doi.org/10.3390/en8076765

28. Saari, J., Sermyagina, E., Kaikko, J., Vakkilainen, E. and Sergeev, V., Integration of Hydrothermal Carbonization and a CHP Plant: Part 2 - Operational and Economic Analysis, Energy, Vol. 113, pp 574-585, 2016, https://doi.org/10.1016/j.energy.2016.06.102

29. Kohl, T., Teles, M., Melin, K., Laukkanen, T., Järvinen, M., Park, S. W. and Guidici, R., Exergoeconomic assessment of CHP-integrated Biomass upgrading, Appl. Energy, Vol. 156, pp 290-305, 2015, https://doi.org/10.1016/j.apenergy.2015.06.047

30. Hannula, I. and Kurkela, E., Liquid Transportation Fuels via Large-Scale Fluidised bed Gasification of Lignocellulosic Biomass, VTT TECHNOLOGY 91, VTT Technical Research Centre of Finland, 2013.

31. Tekin, K., Karagöz, S. and Bektaş, S., Hydrothermal Liquefaction of Beech Wood Using a Natural Calcium Borate Mineral, J. Supercrit. Fluids, Vol. 72, pp 134-139, 2012, https://doi.org/10.1016/j.supflu.2012.08.016

32. Bhaskar, T., Sera, A., Muto, A. and Sakata, Y., Hydrothermal upgrading of Wood Biomass: Influence of the Addition of $\mathrm{K}_{2} \mathrm{CO}_{3}$ and Cellulose/Lignin Ratio, Fuel, Vol. 87, No. 10-11, pp 2236-2242, 2008, https://doi.org/10.1016/j.fuel.2007.10.018

33. Tekin, K., Karagöz, S. and Bektaş, S., Effect of Sodium Perborate Monohydrate Concentrations on Product Distributions from the Hydrothermal Liquefaction of Scotch Pine Wood, Fuel Process. Technol., Vol. 110, pp 17-23, 2013, https://doi.org/10.1016/j.fuproc.2013.01.010

34. Knorr, D., Lukas, J. and Schoen, P., Production of Advanced Biofuels via Liquefaction Hydrothermal Liquefaction Reactor Design, 30352.00/01, National Renewable Energy Laboratory (NREL), 2013, https://doi.org/10.2172/1111191

35. Kohl, T., Laukkanen, T. and Järvinen, M., A Flexible Model for Biomass fast Pyrolysis in Aspen+, Aalto University, Aalto, Finland, 2012.

36. Berglin, E. J., Enderlin, C. W. and Schmidt, A. J., Review and assessment of Commercial Vendors/options for feeding and pumping Biomass Slurries for Hydrothermal Liquefaction, PNNL-21981, Pacific Northwest National Laboratory (PNNL), Richland, WA, US, 2012, https://doi.org/10.2172/1056168

37. Zhu, J. Y. and Pan, X. J., Woody Biomass Pretreatment for Cellulosic Ethanol Production: Technology and Energy Consumption Evaluation, Bioresour. Technol., Vol. 101, No. 13, pp 4992-5002, 2010, https://doi.org/10.1016/j.biortech.2009.11.007

38. Luft, G., Maier, S., Luft, G., Lack, E. and Seidlitz, H., Chapter 7-Safety and Control in High Pressure Plant Design and Operation (A. B. and Vetter, G., ed.), Industrial Chemistry Library, Elsevier, pp 405-435, 2001.

39. Cocero, M. J., Alonso, E., Sanz, M. T. and Fdz-Polanco, F., Supercritical Water Oxidation Process under Energetically Self-Sufficient Operation, J. Supercrit. Fluids, Vol. 24, No. 1, pp 37-46, 2002, https://doi.org/10.1016/S0896-8446(02)00011-6

40. Ibbett, R., Gaddipati, S., Davies, S., Hill, S. and Tucker, G., The Mechanisms of Hydrothermal Deconstruction of Lignocellulose: New Insights from Thermal-analytical and Complementary Studies, Bioresour. Technol., Vol. 102, No. 19, pp 9272-9278, 2011, https://doi.org/10.1016/j.biortech.2011.06.044

41. Poliakoff, M. and Meehan, N., Chapter 9 - Applications (A. B. and Vetter, G., ed.), Industrial Chemistry Library, Elsevier, pp 473-485, 2001.

42. Yang, T., Wang, W., Kai, X., Li, B., Sun, Y. and Li, R., Studies of Distribution Characteristics of Inorganic Elements during the Liquefaction Process of Cornstalk, 
Energy Fuels, Vol. 30, No. 5, pp 4009-4016, 2016, https://doi.org/10.1021/acs.energyfuels.6b00096

43. Madsen, R. B., Biller, P., Jensen, M. M., Becker, J., Iversen, B. B. and Glasius, M., Predicting the Chemical Composition of Aqueous Phase from Hydrothermal Liquefaction of Model Compounds and Biomasses, Energy Fuels, Vol. 30, No. 12, pp 10470-10483, 2016, https://doi.org/10.1021/acs.energyfuels.6b02007

44. Nhien, L. C., Long, N. V. D., Kim, S. and Lee, M., Techno-economic assessment of Hybrid Extraction and Distillation Processes for Furfural Production from Lignocellulosic Biomass, Biotechnol. Biofuels, Vol. 10, 81 p, 2017, https://doi.org/10.1186/s13068-017-0767-3

45. Savola, T. and Keppo, I., Off-design Simulation and Mathematical modeling of Small-scale CHP Plants at Part Loads, Appl. Therm. Eng., Vol. 25, No. 8-9, pp 1219-1232, 2005, https://doi.org/10.1016/j.applthermaleng.2004.08.009

46. Onarheim, K., Lehto, J. and Solantausta, Y., Technoeconomic assessment of a fast Pyrolysis Bio-oil Production Process integrated to a fluidized Bed Boiler, Energy Fuels, Vol. 29, No. 9, pp 5885-5893, 2015, https://doi.org/10.1021/acs.energyfuels.5b01329

47. Tews, I., Zhu, Y., Drennan, C., Elliott, D. C., Snowden-Swan, L., Onarheim, K., Solantausta, Y. and Beckman, D., Biomass Direct Liquefaction Options: TechnoEconomic and Life Cycle Assessment, PNNL-23759, Pacific Northwest National Laboratory, Richland, Washington 99352, USA, 2014.

48. Swanson, R. M., Satrio, J. A., Brown, R. C., Platon, A. and Hsu, D. D., Techno-economic analysis of Biofuels Production Based on Gasification, NREL/TP-6A20-46587, National Renewable Energy Laboratory, 2010, https://doi.org/10.2172/994017

49. How much does a Wastewater treatment System Cost? (Pricing, Factors, Etc.), Samco Tech, [Accessed: 17-May-2017]

50. Peters, M., Timmerhaus, K. and West, R., Plant Design and Economics for Chemical Engineers, McGraw-Hill Education, NY, SAD, 2003.

51. Statistics Finland - Energy - Energy Prices, http://www.stat.fi/til/ehi/index_en.html, [Accessed: 21-May-2017]

52. Schuler, J., Hornung, U., Kruse, A., Dahmen, N. and Sauer, J., Hydrothermal Liquefaction of Lignin, J. Biomater. Nanobiotechnology, Vol. 8, No. 1, 96 p, 2017.

53. Ekpo, U., Ross, A. B., Camargo-Valero, M. A. and Williams, P. T., A Comparison of Product Yields and Inorganic Content in Process Streams Following Thermal Hydrolysis and Hydrothermal Processing of Microalgae, Manure and Digestate, Bioresour. Technol., Vol. 200, pp 951-960, 2016, https://doi.org/10.1016/j.biortech.2015.11.018

54. Liu, Z. and Zhang, F.-S., Effects of Various Solvents on the Liquefaction of Biomass to produce Fuels and Chemical Feedstocks, Energy Convers. Manag., Vol. 49, No. 12, pp 3498-3504, 2008, https://doi.org/10.1016/j.enconman.2008.08.009

55. Gustavsson, C. and Hulteberg, C., Co-production of Gasification based Biofuels in Existing Combined Heat and Power Plants - Analysis of Production Capacity and Integration Potential, Energy, Vol. 111, pp 830-840, 2016, https://doi.org/10.1016/j.energy.2016.06.027 